\title{
Transcription Factor AtMYB44 Regulates Induced Expression of the ETHYLENE INSENSITIVE2 Gene in Arabidopsis Responding to a Harpin Protein
}

\author{
Ruoxue Liu,, ${ }^{1,2}$ Lei Chen,, ${ }^{1,3}$ Zhenhua Jia,, ${ }^{1,4}$ Beibei Lü, ${ }^{1}$ Haojie Shi, ${ }^{1}$ Weilan Shao, ${ }^{2}$ and Hansong Dong ${ }^{1}$ \\ ${ }^{1}$ State Ministry of Agriculture of R. P. China Key Laboratory of Monitoring and Management of Crop Pathogens and Insect \\ Pests, Nanjing Agricultural University, Nanjing, 210095, China; ${ }^{2}$ College of Life Sciences, Nanjing Normal University, Nanjing, \\ 210046, China; ${ }^{3}$ Institute of Utilization of Nuclear Techniques, Zhejiang Academy of Agricultural Sciences, Hangzhou, 310021, \\ China; ${ }^{4}$ Biology Institute, Hebei Academy of Science, 46 Southern Street of Friendship, Shijiazhuang 050051, China
}

Submitted 27 July 2010. Accepted 18 November 2010.

\begin{abstract}
AtMYB44 is a transcription factor that functions in association with the ethylene-signaling pathway in Arabidopsis thaliana. The pathway depends on ETHYLENE INSENSITIVE2 (EIN2), an essential component of ethylene signaling, to regulate defense responses in the plant following treatment with $\mathrm{HrpN}_{\mathrm{Ea}}$, a harpin protein from a bacterial plant pathogen. Here, we show that AtMYB44 regulates induced expression of the EIN2 gene in $\mathrm{HrpN}_{\mathrm{Ea}}$-treated Arabidopsis plants. A $\mathrm{HrpN}_{\mathrm{Ea}}$ and ethylene-responsive fragment of the $A t M Y B 44$ promoter is sufficient to support coordinate expression of $A t M Y B 44$ and $E I N 2$ in specific transgenic Arabidopsis. In the plant, the AtMYB44 protein localizes to nuclei and binds the EIN2 promoter; the $\mathrm{HrpN}_{\mathrm{Ea}}$ treatment promotes AtMYB44 production, binding activity, and transcription of AtMYB44 and EIN2. AtMYB44 overexpression results in increased production of the AtMYB44 protein and the occurrence of AtMYB44-EIN2 interaction under all genetic backgrounds of wild-type Arabidopsis and the etr1-1, ein2-1, ein3-1, and ein5-1 mutants, which have defects in the ethylene receptor ETR1 and the signal regulators EIN2, EIN3, and EIN5. However, $A t M Y B 44$ overexpression leads to enhanced EIN2 expression only under backgrounds of wild type, ein3-1, and ein5-1 but not etr1-1 and ein2-1, suggesting that ethylene perception is necessary to the regulation of EIN2 transcription by AtMYB44.
\end{abstract}

AtMYB44 is a transcription factor known to be involved in embryogenesis (Kirik et al. 1998), seed maturation (Kirik et al. 1998), and responses to pathogens (Kranz et al. 1998; Liu et al. 2010; Pitzschke et al. 2009), insects (Liu et al. 2010), and environmental stresses (Jung et al. 2007, 2008, 2010) in Arabidopsis thaliana. The multiple functions of AtMYB44 are related to ethylene (Chen et al. 2006; Liu et al. 2010) and several other phytohormones (Chen et al. 2006; Jung et al. 2008, 2010; Kranz et al. 1998) that induce expression of the AtMYB44 gene. Based on a comparison of 45 Arabidopsis $M Y B$ genes in terms of responses to the phytohormones, ethylene is the most effec-

R. Liu, L. Chen, Z. Jia, B. Lü, and H. Shi contributed equally to this work.

Corresponding author: H. Dong E-mail: hsdong@njau.edu.cn; Telephone: +862584399006 or +86 13813928425; Fax: +86 2584396246 .

* The $\boldsymbol{e}$-Xtra logo stands for "electronic extra" and indicates that seven supplementary figures and one supplementary table are published online. tive inducer of AtMYB44 transcription (Chen et al. 2006). In 37 ethylene-inducible transcription factor genes we tested recently, AtMYB44 is the most responsive to ethylene (Liu et al. 2010).

Ethylene is a gaseous phytohormone that mediates multiple aspects of plant growth, development, and defense responses (Lin et al. 2009; Sun et al. 2010; Wang et al. 2002; Zhu and Guo 2008). In Arabidopsis, ethylene signaling activates different regulators to fulfill distinct functions (Camehl et al. 2010; Chen et al. 2009). ETHYLENE INSENSITIVE2 (EIN2) is an integral membrane protein, is an essential regulator of ethylene signaling, and therefore, is indispensable for the multiple processes (Alonso et al. 1999; Camehl et al. 2010; Wang et al. 2002). EIN2 relies on the C-terminal region (EIN2-CEND) to confer most ethylene responses of Arabidopsis (Alonso et al. 1999; Penmetsa et al. 2008). In the plant, ethylene positively regulates EIN2 accumulation by modulating EIN2 TARGETING PROTEINS 1 and 2 (ETP1 and ETP2) that interact with EIN2-CEND. ETP1 and ETP2 accumulate and act to decompose EIN2 in the absence of ethylene. Inversely, ethylene downregulates ETP1 and ETP2, impairs their interactions with EIN2, and thus, protects EIN2 from decomposition (Qiao et al. 2009). This regulatory mechanism contributes to the stability and turnover of EIN2, which are essential for triggering ethylene responses (Qiao et al. 2009; Wang et al. 2009). This mechanism is impaired in the EIN2-mutated ein2 alleles. The ein2-1 allele, for example, is responsible for a frame stop upstream of the long intracellular region of the EIN2 protein sequence (Alonso et al. 1999). This mutation renders the plant insensitive to ethylene (Guzman and Ecker 1990) and alters several characteristics, such as responses to environmental stresses and insect attacks (Dong et al. 2004; Leon-Reyes et al. 2009). The ethylene insensitivity also results in a reduction in the levels of both EIN2 mRNA (Alonso et al. 1999) and EIN2 protein in Arabidopsis ein 2 mutants (Qiao et al. 2009). Therefore, transcription of the EIN2 gene correlates with accumulation of the EIN2 protein in the ethylene regulatory mechanism. However, whether transcriptional regulation of EIN2 plays a role in ethylene signaling has long been in question.

The ethylene-signaling pathway is activated when the ethylene level is elevated in plants treated with elicitors (Wang et al. 2002), such as harpin proteins produced by gram-negative plant-pathogenic bacteria (Kim and Beer 2000). $\mathrm{HrpN}_{\mathrm{Ea}}$ is a harpin secreted by Erwinia amylovora, the bacterial pathogen that causes fire blight disease in rosaceous plants (Wei et al. 1992). External application of $\mathrm{HrpN}_{\mathrm{Ea}}$ induces defense responses in a variety of plant species (Kim and Beer 2000), and 
the induced defense effectively protects plants from infestations of insects (Dong et al. 2004; Liu et al. 2010). In Arabidopsis, ethylene and EIN2 are required for $\mathrm{HrpN}_{\mathrm{Ea}}$ to induce resistance against infestation of the green peach aphid (Myzus persicae Sulzer). The extrinsic use of $\mathrm{HrpN}_{\mathrm{Ea}}$ inhibits aphid multiplication on the plant. This effect is induced in wild-type (WT) Arabidopsis rather than in the ein2-1 and etr1-1 mutants (Dong et al. 2004). The etrl-1 mutant has a defect in the ethylene receptor ETR1 (Bleecker et al. 1988), which functions upstream of EIN2 in ethylene signal transduction (Guo and Ecker 2004). Therefore, perception of the ethylene signal and its transduction to EIN2 are critical for the induction of insect defense.
To elucidate a regulatory mechanism by which EIN2 contributes to insect defense, we recently studied 37 Arabidopsis transcription factor genes that respond to ethylene and $\mathrm{HrpN}_{\mathrm{Ea}}$ (Liu et al. 2010). In response, 22 genes increased in transcription levels, with AtMYB44 being the most inducible. Nine of 37 Arabidopsis mutants with defects in individual genes were more susceptible than WT to aphid infestations. Greater extents of susceptibility were found in atmyb15, atmyb38, and atmyb44. The atmyb44 mutant that had been disrupted in AtMYB44 promoter region was most compromised in induced resistance. Resistance accompanied the expression of PDF1.2, a gene that is associated with insect defenses (Moran and Thompson 2001) and requires EIN2 for transcription (Alonso

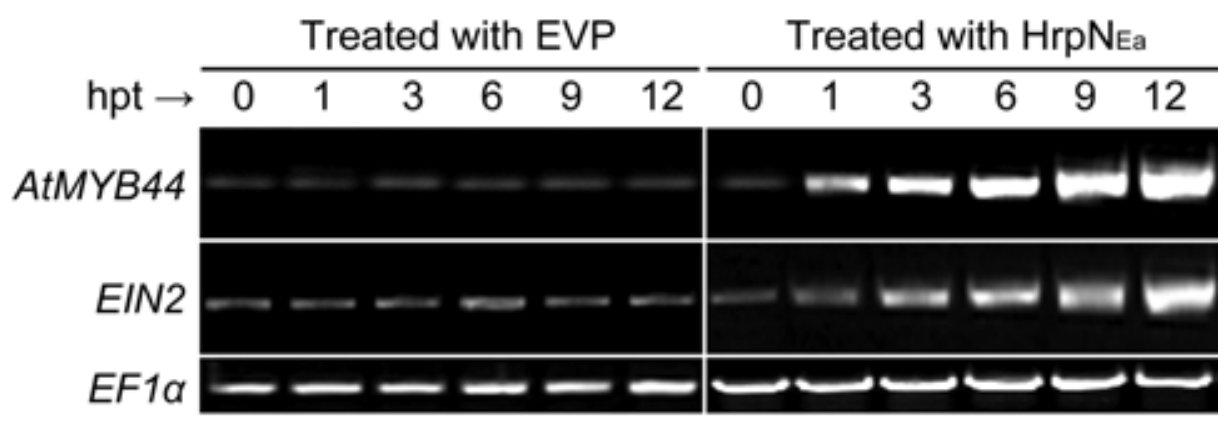

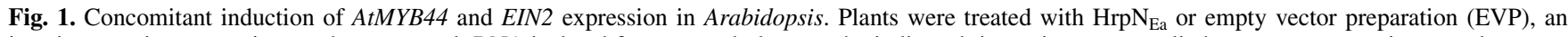
inactive protein preparation used as a control. RNA isolated from treated plants at the indicated timepoints, was applied to reverse transcriptase-polymerase chain reaction using the $E F 1 \alpha$ gene as a reference. hpt = hour posttreatment,

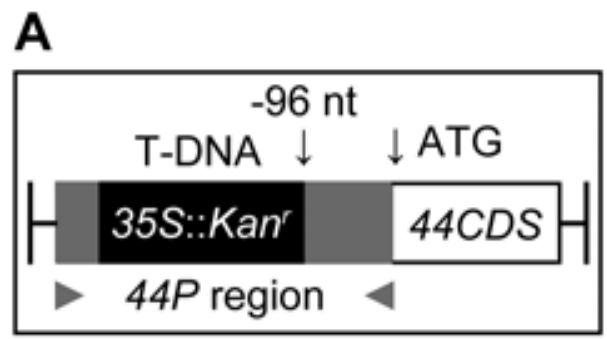

B

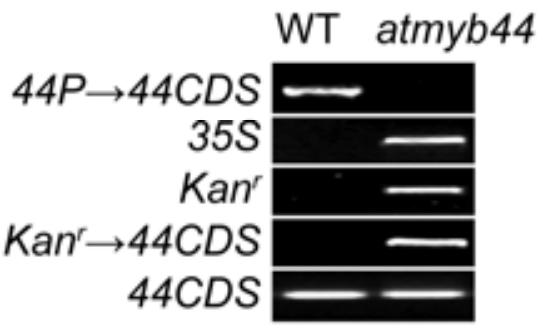

C

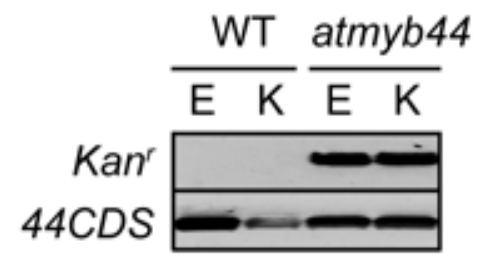

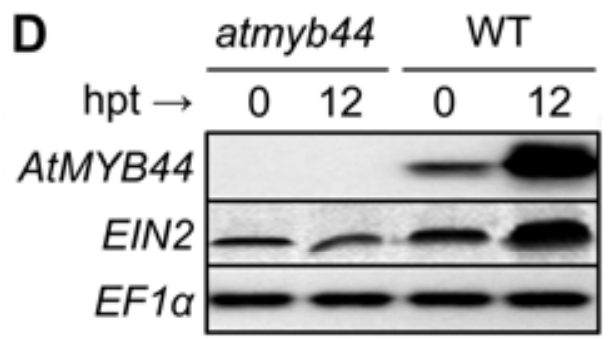

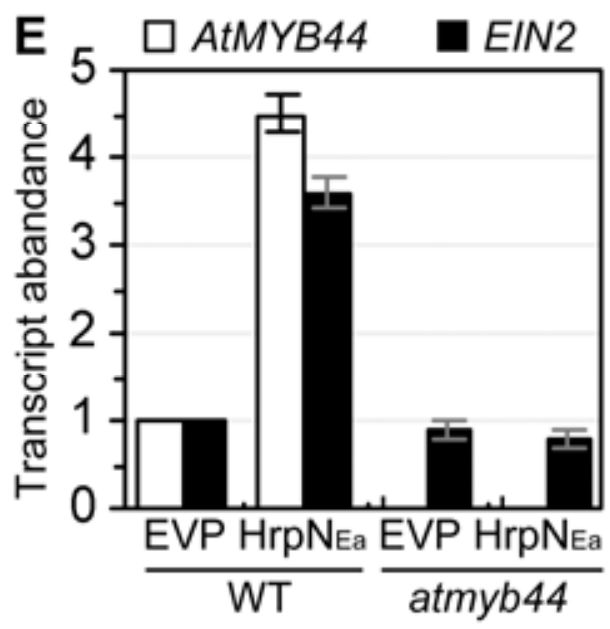

Fig. 2. Analyses of the Arabidopsis mutant atmyb44 and its effects on AtMYB44 and EIN2 expression. A, The atmyb44 mutant was generated by T-DNA insertion via a vector containing the Cauliflower mosaic virus $35 \mathrm{~S}$ promoter $(35 \mathrm{~S})$ and kanamycin-resistant gene $\left(\mathrm{Kan}^{\prime}\right)$. The T-DNA insert is located at the -96-nucleotide (nt) residue of the AtMYB44 DNA sequence. 44P = AtMYB44 promoter, ATG $=$ transcription start, and 44CDS = AtMYB44 coding sequence. B, T-DNA insertion in atmyb44, compared with wild type (WT), was confirmed by polymerase chain reaction (PCR) analysis using genomic DNA and primers specific for the indicated sequences. C, WT and atmyb44 genomic DNA samples were digested with EcoRI (E) and KpnI (K), respectively. Digested DNA samples were resolved by 25-min gel electrophoresis. The blot was hybridized with the indicated probes. D, Northern blot analyses of AtMYB44 and EIN2 were conducted using the $E F 1 \alpha$ gene to verify consistent loading of RNA samples from $\mathrm{HrpN}_{\mathrm{Ea}}$-treated plants. hpt $=$ hours posttreatment $\mathbf{E}$, Real-time reverse transcriptase-PCR was used to quantify levels of gene expression in plants 12 hpt. Transcript abundance was defined as 1 for empty vector preparation (EVP)-treated WT and was scored accordingly for other plants. Data represent means \pm standard deviation (SD) (three repeats, 15 plants per repeat). 
et al. 1999). PDF1.2 was expressed in WT but not in atmyb15, atmyb38, and atmyb44, whereas only atmyb44 incurred an abrogation in induced EIN2 expression (Liu et al. 2010). This article reports the role of AtMYB44 in regulating the induction of EIN2 expression. The effects of AtMYB44 on $\mathrm{HrpN}_{\mathrm{Ea}^{-}}$ induced and insect-induced resistance to insects are reported in companion articles (Liu et al. 2010; Zhang et al. in press).

\section{RESULTS}

AtMYB44 expression is coordinate with AtMYB44-dependent EIN2 expression in response to $\mathrm{HrpN}_{\mathrm{Ea}}$ application.

To gain information about the functional relationship between AtMYB44 and EIN2, we determined the expression of both genes in Arabidopsis following treatment with $\mathrm{HrpN}_{\mathrm{Ea}}$. For use in this study, $\mathrm{HrpN}_{\mathrm{Ea}}$ was produced using a prokaryotic expression vector containing an insert of the $h r p N_{E a}$ gene (Wei et al. 1992), and the empty vector preparation (EVP), based on the vector only, was used as a control (Dong et al. 1999; Peng et al. 2003). As shown in Figure 1, reverse transcriptase-polymerase chain reaction (RT-PCR) detected concomitant AtMYB44 and EIN2 expression in WT plants treated with EVP or $\mathrm{HrpN}_{\mathrm{Ea}}$ at different intervals of time. In EVP-treated plants, AtMYB44 and EIN2 showed constitutive expression as observed immediately after treatment, 0 through $12 \mathrm{~h}$ posttreatment (hpt). In contrast, the amounts of both gene transcripts increased during the same period of time following the application of $\mathrm{HrpN}_{\mathrm{Ea}}$. The overlapping temporal expression patterns of AtMYB44 and EIN2 in response to $\mathrm{HrpN}_{\mathrm{Ea}}$ application suggested that both genes were coordinate in transcriptional regulation.

As in WT plants, AtMYB44 and EIN2 also behaved coordinately in atmyb44, an Arabidopsis mutant generated previously through T-DNA insertion at the promoter region of AtMYB44 (Fig. 2A). We chose to use this mutant because the mutation mode fit our study's purpose of addressing the function of inducible AtMYB44 expression. Mutagenesis was confirmed by PCR analysis (Fig. 2B). Southern blot hybridization revealed a single copy of the T-DNA insert in the atmyb44 genome (Fig. 2C). This mutation not only canceled AtMYB44 transcription but also reduced the level of EIN2 expression, based on Northern blot analyses of transcripts from WT and atmyb44

A 44P2000::44CDS::GFP

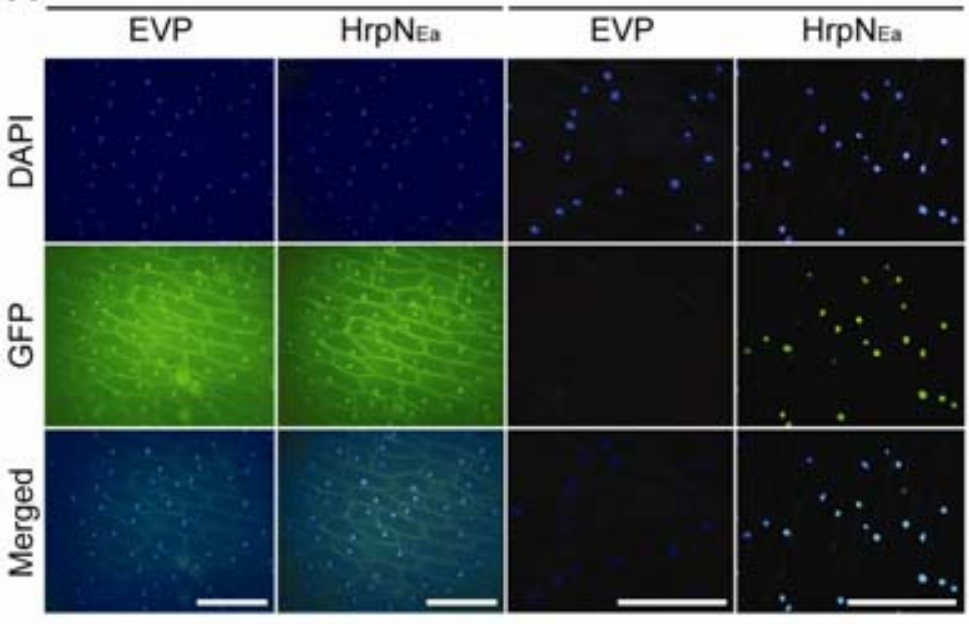

B

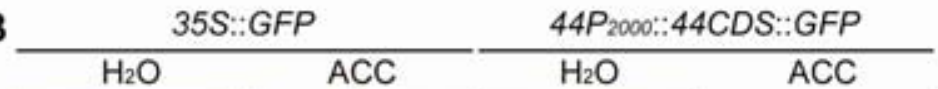

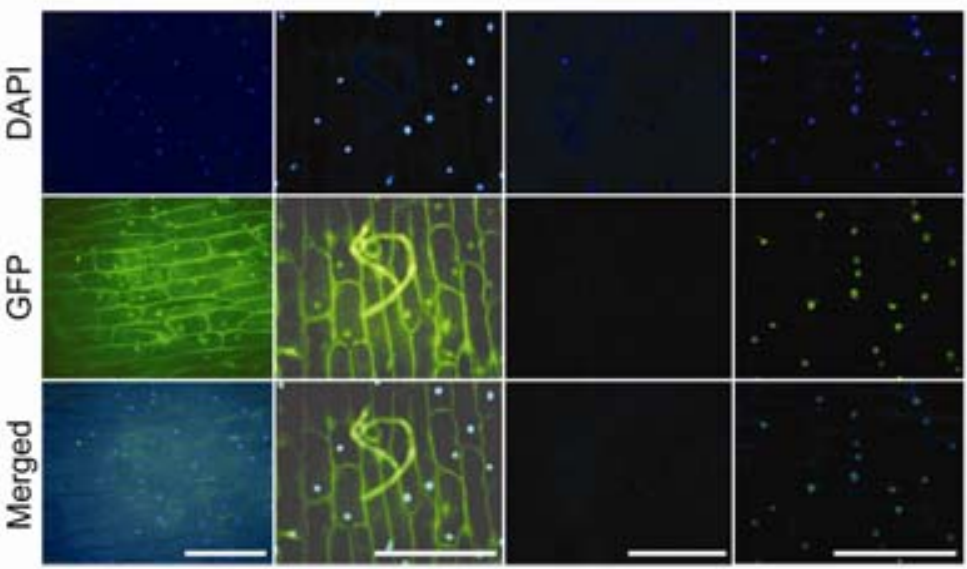

Fig. 3. Inducible activity of the 2,000-bp fragment of AtMYB44 promoter $\left(44 P_{2000}\right)$ tested in comparison with Cauliflower mosaic virus $35 S$ promoter $(35 S)$. A, Onion peels were transformed with $44 P_{2000}: 44 C D S:: G F P$ or $35 S:: G F P$ in the presence of empty vector preparation (EVP) and HrpN $\mathrm{Ea}_{\text {, }}$ respectively. After $48 \mathrm{~h}$, transformed onion peels were stained with 4,6-diamidino-2-phenylindole (DAPI) and were observed under a fluorescence microscope to visualize DAPI-stained nuclei and green fluorescent protein (GFP) fluoluminescence. Both types of images were merged using the Adobe Photoshop tool. B, Onion peels were transformed in the presence of ethylene converted from the precursor 1-aminocyclopropane-1-carboxylate (ACC) and were observed $48 \mathrm{~h}$ later. Sample staining and observations were the same as in A. In A and B, each photo represents 75 onion peel samples from three experimental repetitions; scale bar $=25 \mu \mathrm{m}$, applied to the vertical photo panels. 
plants following treatment with $\operatorname{HrpN}_{\mathrm{Ea}}$ (Fig. 2D). Real-time RT-PCR (Supplementary Fig. S1) detected 4.5- and 3.6-fold increases of AtMYB44 and EIN2 transcripts, respectively, in $\mathrm{HrpN}_{\mathrm{Ea}}$-treated WT plants between 0 and $12 \mathrm{hpt}$ (Fig. 2E). The effect of $\mathrm{HrpN}_{\mathrm{Ea}}$ treatment was canceled in atmyb44 (Fig. 2E). In both Northern and real-time RT-PCR analyses, the steadystate level of EIN2 transcript in atmyb44 was similar to that in WT (Fig. 2D and E). Thus, induced EIN2 expression was AtMYB44-dependent.

\section{Nuclear localization of the AtMYB44 protein promotes AtMYB44-dependent EIN2 expression.}

A fragment obtained by truncating the WT AtMYB44 promoter was tested for promoter activity. The fragment covers the upstream 2,000 nucleotides of the AtMYB44 promoter and was, thus, designated as $44 P_{2000}$. In onion peels, the activity of $44 P_{2000}$ was induced by $\mathrm{HrpN}_{\mathrm{Ea}}$ treatment, to drive the expression of WT AtMYB44 coding sequence (44CDS), which had been fused to GFP, a green fluorescent protein (GFP) gene (Fig. 3A). In contrast to the cellular ubiquitous distribution of only GFP under the control of the Cauliflower mosaic virus $35 S$ promoter $(35 S)$, the AtMYB44-GFP fusion protein under the control of $44 P_{2000}$ exclusively localized to the nuclei in onion peels treated with $\mathrm{HrpN}_{\mathrm{Ea}}$ as compared with EVP. The activity of $44 P_{2000}$ was corroborated as ethylene responsive using ethylene and its precursor 1-aminocyclopropane-1-carboxylate (ACC) (Fuhrer et al. 1982; Ghassemian et al. 2000). Both compounds were applied to onion peels in sealed jars. When ACC was applied to onion peels transformed with $44 P_{2000}:: 44 C D S:: G F P$, the $44 C D S-G F P$ fusion protein localized exclusively to the nuclei, whereas, the GFP protein was distributed throughout the cells transformed with $35 S:: G F P$ (Fig. 3B). Because, to our knowledge, there was no report about the use of ACC in onion peels, we determined whether ACC was converted into ethylene. In $2 \mathrm{~h}$ after onion peels were placed in sealed glass jars amended with ACC, concentrations of ethylene in jars reached to $20 \mu \mathrm{l} /$ liter, in contrast to $0.3 \mu \mathrm{l} /$ liter released from plants in water-amended jars. In addition, ethylene was applied directly during transformation of onion peels with $44 P_{2000}:: 44 C D S:: G F P$ and subsequent incubation. In this case, 44CDS-GFP localized exclusively to the nuclei, in contrast to the absence of the protein in control onion cells (Supplementary Fig. S2). Therefore, ethylene either applied directly or converted from ACC had similar effects on the activity of $44 P_{2000}$, and ACC was used consistently for the treatment convenience in further studies. These results identified $44 P_{2000}$ as a $\mathrm{HrpN}_{\mathrm{Ea}}$ and ethylene-inducible fragment of the WT AtMYB44 promoter.

To determine whether $44 P_{2000}$ functions to drive $44 C D S$ expression in Arabidopsis, the 2,000-bp ethylene/ $\mathrm{HrpN}_{\mathrm{Ea}}$-responsive fragment of the AtMYB44 promoter was fused to the AtMYB44 coding sequence, GFP, and a His tag for nine tandem histidine residues. The cassette, $44 P_{2000}: 44 C D S:: G F P:: H i s$, was cloned into a binary vector (Fig. 4A) and was transferred into atmyb44 plants. From 150 independent $44 P_{2000}:: 44 C D S:$ : GFP::His lines examined, 10 lines were characterized for the genomic integration (Fig. 4B) and induced expression of the transgene (Fig. 4C) as well as the restoration of WT characteristics (Supplementary Fig. S3). The transgenic lines were designated as genetically complemented atmyb44 (Catmyb44) plants, regarding restoration of inducibility of AtMYB44 and EIN2 by $\mathrm{HrpN}_{\mathrm{Ea}}$ (Figs. 4 and 5). The restoration of WT characteristics was also observed in the processes known to be affected by atmyb44. The atmyb44 mutant was identified as early flowering and was impaired in drought stress-induced stomatal closure (Jung et al. 2008; Liu et al. 2010). In longday experiments, Catmyb44 plants flowered at the same time as WT, 12 days later than the parental atmyb44 plants. As a typical cytological response to drought stress, stomatal closure can be induced effectively by the physiological drought inducer polyethylene (Dong et al. 2005). Stomatal closure was induced in response to polyethylene treatment in both Catmyb44 and WT plants but was not observed in atmyb44. Clearly, the genetic complementation of atmyb44 retrieved the mutant to WT in the tested characteristics.

The genetic complementation also restored atmyb44 to WT in response to $\mathrm{HrpN}_{\mathrm{Ea}}$. $\mathrm{HrpN}_{\mathrm{Ea}}$-induced AtMYB44 expression was detected in all the 10 Catmyb44 lines as in WT, and Catmyb44-2, Catmyb44-7, and Catmyb44-9 accumulated the highest, the lowest, and moderate amounts of AtMYB44 transcript, respectively (Fig. 4D). Genomic integration of the transgene was confirmed by Southern blot hybridization, showing two, one, and three copies of the transgene, in Catmyb44-2, Catmyb44-7, and Catmyb44-9, respectively (Fig. 5A). In response to $\mathrm{HrpN}_{\mathrm{Ea}}$, AtMYB44 expression (Fig. 4C) accompanied the production of the AtMYB44-GFP-His fusion protein (Fig. $5 \mathrm{~B}$ ), and the amount of transcript was directly correlated to the amount of protein (Fig. 4D) in the three Catmyb44 lines, in contrast to WT and atmyb44. Catmyb44-2 was tested throughout this study because it had the highest level of AtMYB44 expression (Fig. 4D) and the greatest amount of the fusion protein (Fig. 5B). The fusion protein was produced and localized to the nuclei of Catmyb44-2, following treatment with $\mathrm{HrpN}_{\mathrm{Ea}}$ (Fig. 5C) and ACC (Supplementary Fig. S4), respectively, providing the possibility that AtMYB44 acted to regulate the transcription of EIN2 under the induction treatment conditions. Conforming to this notion, AtMYB44 expression (Fig. 5D) and AtMYB44-dependent EIN2 expression (Fig. 5E), attenuated in atmyb44, were recovered to WT levels in the complemented plants following treatment with $\mathrm{HrpN}_{\mathrm{Ea}}$. In the absence of $\mathrm{HrpN}_{\mathrm{Ea}}$ treatment, however, the steady-state level of EIN2 transcript was close in WT, atmyb44, and the Catmyb44 lines (Fig. $5 \mathrm{E})$. Therefore, the genetic complementation in atmyb44 resulted in coordinate induction of AtMYB44 gene expression, nuclear localization of the AtMYB44 protein, and AtMYB44dependent EIN2 expression.

\section{AtMYB44 targets EIN2.}

To elucidate the physiological basis of AtMYB44-dependent EIN2 expression, AtMYB44 activity in binding the consensus MYB recognition sequence (CMRS) 5'-TAACTG-3' (Abe et al. 2003; Hoeren et al. 1998; Urao et al. 1993, 1996) found in the EIN2 promoter sequence $(-2.690)$ was tested by gel mobility shift assay (GMSA). For use in the assay, AtMYB44 was fused to a His-tag that codes for six tandem histidine residues by cloning in the pET30a(+) vector, and the AtMYB44-His fusion protein was produced in a prokaryotic expression system (Supplementary Fig. S5A). In GMSA with unpurified proteins, biotin-labeled WT probe bound AtMYB44::His, in contrast to the inactive protein preparation (PET) used as a control (Supplementary Fig. S6). For use in a confirmative test, the AtMYB44-His fusion protein preparation was partially purified in comparison with PET. GMSA done with multiple competitors and partially purified AtMYB44-His protein disclosed the specific activity of AtMYB44 in binding the probe (Fig. $6 \mathrm{~A})$.

The specificity was also found in GMSA that involved biotin-labeled WT probe (B1-WT-P) and AtMYB44::His in combination with a range of concentrations of unlabeled WT probe (WT-P). As shown in Figure 6B, the specific interaction between AtMYB44::His and Bl-WT-P was detected when the WT-P concentration was lowered to $5 \times 10^{-4} \mu \mathrm{mol}$. The assay also indicated that the combination of $5 \times 10^{-8} \mu \mathrm{mol}$ Bl-WT-P and $5 \times 10^{-2} \mu \mathrm{mol}$ AtMYB44::His were desired to show the 
specific AtMYB44 activity. Moreover, the specific activity was confirmed by GMSA using a specific anti-His antibody, B1WT-P, and nuclear proteins isolated from $\mathrm{HrpN}_{\mathrm{Ea}}$-treated Catmyb44-2 (Fig. 6C). When the reaction solution contained Bl-WT-P and nuclear proteins but the antibody was excluded, the DNA-protein complex containing Bl-WT-P and AtMYB44 appeared, in contrast to its absence in the controls, indicating the interaction between the specific probe and AtMYB44::His present in nuclear proteins. When the antibody was used in combination with the probe and nuclear proteins, the DNA-
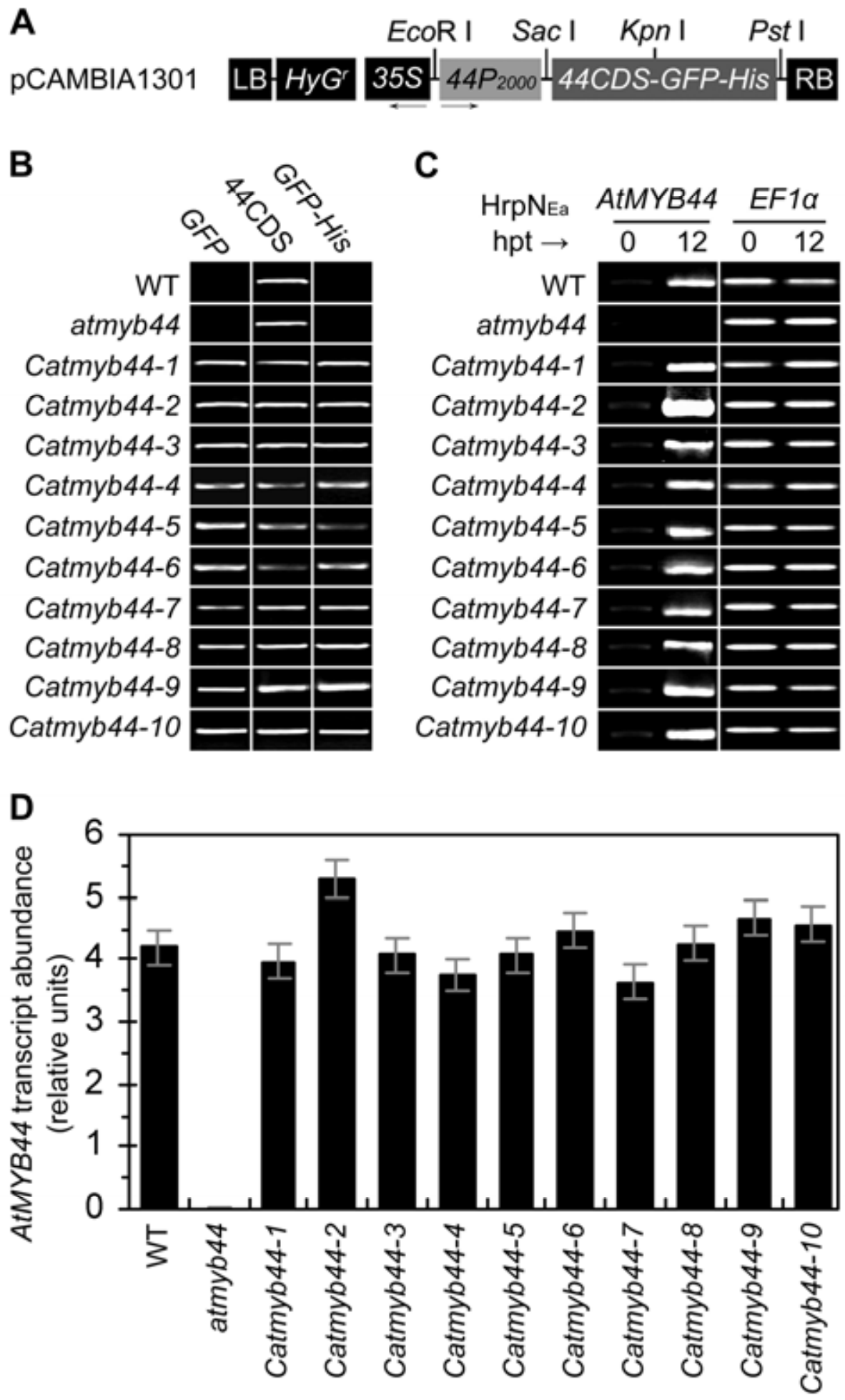

Fig. 4. Characterization of atmyb44-complemented (Catmyb44) plants. A, The recombinant vector was used to transform atmyb44 and generate Catmyb44 lines. $H y G^{r}$ refers to hygromycin-resistant gene. Enzyme restriction sites and two independent transcription units are indicated by arrow heads. B, Polymerase chain reaction (PCR) analysis of the indicated genes (top) was done using genomic DNA from plants (left) without treatment. C, reverse transcriptase (RT)-PCR was done with RNA isolated at 0 and $12 \mathrm{~h}$ posttreatment (hpt) from plants treated with empty vector preparation or HrpN $\mathrm{Ea}_{\mathrm{Ea}}$. D, Total RNA isolated at 0 and $12 \mathrm{hpt}$ from $\mathrm{HrpN}_{\mathrm{Ea}}$-treated plants was analyzed by real-time RT-PCR, using AtMYB44-specific primers. For quantitative comparison, the transcript abundance was defined as 1 for wild-type (WT) plants at $0 \mathrm{hpt}$. The histogram represents relative levels (means \pm standard deviation, three repeats, 15 plants per repeat) of AtMYB44 expression at $12 \mathrm{hpt}$. 
protein complex containing B1-WT-P, AtMYB44, and antibody (AB) appeared, while the complex without $\mathrm{AB}$ declined, indicating the specific activity of AtMYB44.

Further evidence supporting the specific AtMYB44 activity was obtained from the chromatin immunoprecipitation (ChIP) assay, which revealed direct interaction between AtMYB44 and EIN2 (Fig. 6D). The assay was conducted with chromatin isolated from $\mathrm{HrpN}_{\mathrm{Ea}}$-treated Catmyb44-2 and the specific antiHis antibody. When a DNA sample from the 44IP complex (chromatin DNA+AtMYB44::His+antibody) was used as a tem-
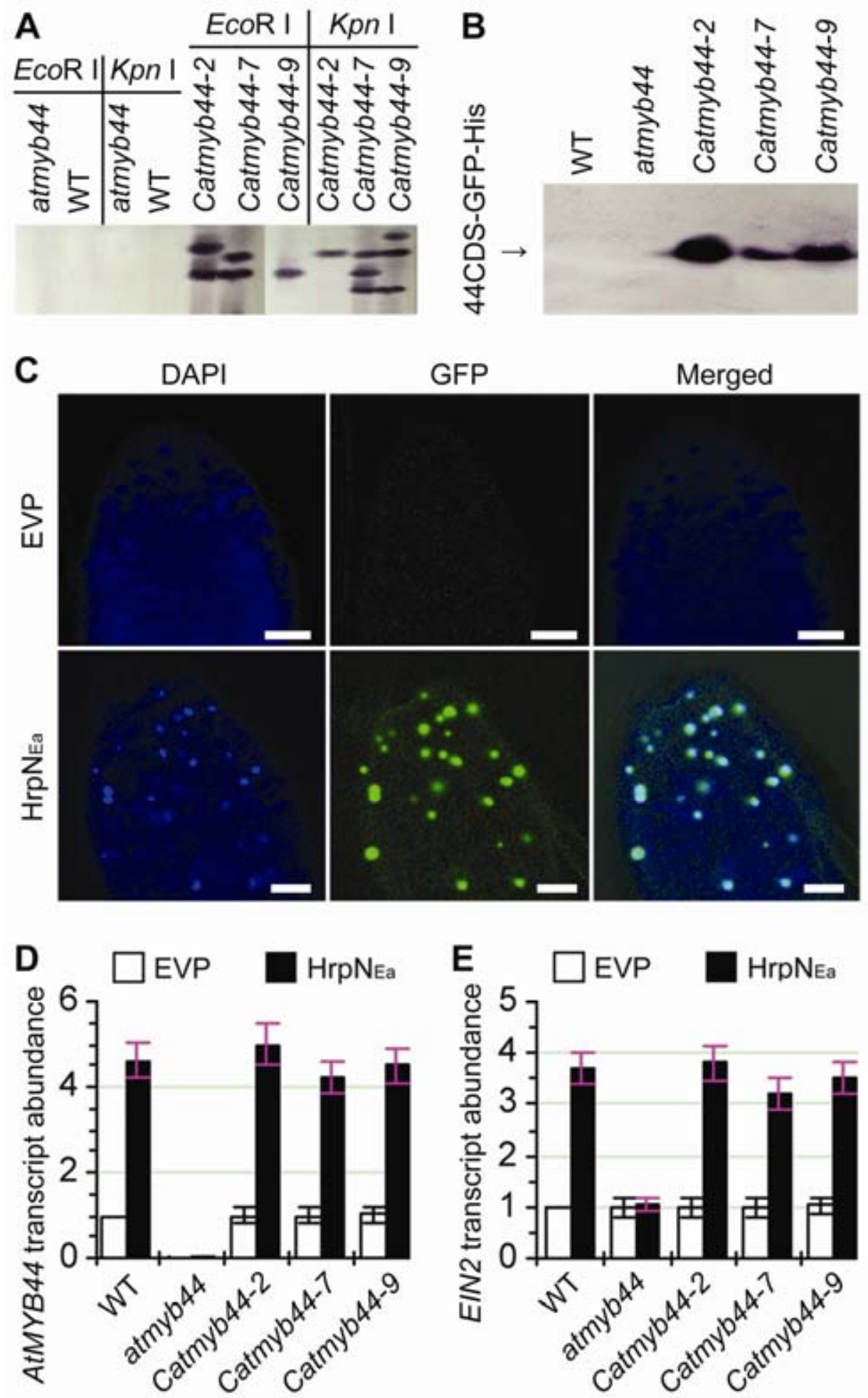

Fig. 5. Analyses of representative Catmyb44 lines and their effects on AtMYB44 and EIN2 expression. A, The Southern blot hybridized with the hygromycinresistant gene $\left(H y G^{r}\right)$-specific probe. The genomic DNA had been digested with the indicated enzymes and resolved by 2-h gel electrophoresis. B, The Western blot of leaf proteins was incubated with anti-His antibody and was hybridized with horseradish peroxidase-conjugated goat antimouse immunoglobulin G. C, Catmyb44-2 roots were treated by immersion in a solution of empty vector preparation (EVP) or $\mathrm{HrpN}_{\mathrm{Ea}}$. After $12 \mathrm{~h}$, root samples were stained with 4,6-diamidino-2-phenylindole and were observed by confocal microscopy. Scale bar $=25 \mu \mathrm{m}$. D and E, Real-time reverse transcriptase-polymerase chain reaction was done using RNA isolated at $12 \mathrm{~h}$ posttreatment from plants treated with EVP or $\mathrm{HrpN}_{\mathrm{Ea}}$. Transcript abundance was defined as 1 for EVP-treated wild type (WT) and was scored (mean \pm SD, three repeats, 15 plants per repeat) accordingly for other plants. 
plate, a product was obtained by PCR using EIN2-specific primers. When a similar precipitation process was conducted in the absence of the antibody, the PCR protocol did not yield any product. The product from 44IP was similar to that amplified from DNA templates in two types of inputs, chromatins without immunoprecipitation (input, $-\mathrm{AB}$ ) and supernatants from immunoprecipitation (input, $+\mathrm{AB}$ ). The sequences of the three products were confirmed as EIN2.

\section{AtMYB44-EIN2 interaction and expression of $A t M Y B 44$ and EIN2 are coordinately promoted by $\operatorname{HrpN}_{\mathrm{Ea}}$ application.}

Based on densities of complexes shown in Figure 6C, nuclear proteins isolated from $\mathrm{HrpN}_{\mathrm{Ea}}$-treated Catmyb44-2 plants bound considerably more probe than EVP-treated plants. Since nuclear proteins used in electrophoresis and GMSA were consistently isolated from $2 \mathrm{~g}$ of fresh leaves, increased densities of protein bands (Fig. 7A) and increased densities of the AtMYB44-probe complex (Fig. 7B) represented a true increase in concentration and the probe-binding activity of AtMYB44. In Catmyb44-2, $\mathrm{HrpN}_{\mathrm{Ea}}$ treatment induced the production of the AtMYB44-His fusion protein, which markedly increased in concentration with time for $18 \mathrm{hpt}$ (Fig. 7A). Induced AtMYB44 expression caused more binding in GMSA (Fig. 7B). The concentration and activity of AtMYB44::His were elevated with overlapping temporal patterns during the course of time after $\mathrm{HrpN}_{\mathrm{Ea}}$ application (Fig. 7A and B). Thus, the promoted AtMYB44 activity might be attributed to elevated content of the protein.

This notion was confirmed by ChIP PCR conducted with chromatins, the specific anti-His antibody, and EIN2-specific primers. Chromatins used in the assays were isolated at intervals from 0 to $18 \mathrm{hpt}$ from leaves of $\mathrm{HrpN}_{\mathrm{Ea}}$-treated plants.
Primers specific to EIN2 CDS (Fig. 7C, section a) and the promoter region (Fig. 7C, section b) were used with similar results. ChIP PCR detected EIN2 DNA from $\mathrm{HrpN}_{\mathrm{Ea}}$-treated plants of Catmyb44-2 but not from WT and atmyb44, because the AtMYB44-His fusion protein was produced in Catmyb44-2 but not in WT and atmyb44. The EIN2 sequence was amplified by PCR using the DNA template from Catmyb44-2 44IP in a way similar to that amplified by PCR using DNA templates from supernatants from immunoprecipitation (input 1) and the chromatins before immunoprecipitation (input 2). In contrast, the EIN2 sequence was not obtained when ChIP PCR was done in the absence of the antibody $(-\mathrm{AB})$. Because the same amounts of chromatins from different plant samples were used in the ChIP assays, densities of the PCR products represented the relative proportion of AtMYB44-His bound with EIN2 DNA in the chromatins. Based on amounts of EIN2 DNA, the AtMYB44:: His fusion protein in Catmyb44-2 increased dramatically between 3 and 18 hpt (Fig. 7C). Moreover, the AtMYB44-EIN2 interaction was identified from Catmyb44-7 and Catmyb44-9 as in Catmyb44-2 (Supplementary Fig. S7), suggesting that AtMYB44 targeting of EIN2 was a consistent characteristic of Catmyb44.

The promotion in both AtMYB44 production and AtMYB44EIN2 interaction accompanied an enhancement in AtMYB44 and EIN2 expression (Fig. 7D and E). Based on RT-PCR analyses, the amount of AtMYB44 transcript increased with time following $\mathrm{HrpN}_{\mathrm{Ea}}$ treatment in WT and Catmyb44-2 tested in comparison with atmyb44 (Fig. 7D). Real-time RT-PCR data showed the overlapping temporal expression patterns of EIN2 and AtMYB44 genes during the course of time after $\mathrm{HrpN}_{\mathrm{Ea}}$ application to WT and Catmyb44 (Fig. 7E). AtMYB44 and EIN2 were expressed at lower levels at $3 \mathrm{hpt}$ and with both tran-
A

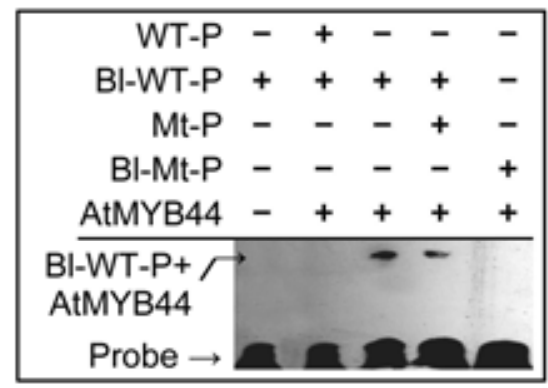

D

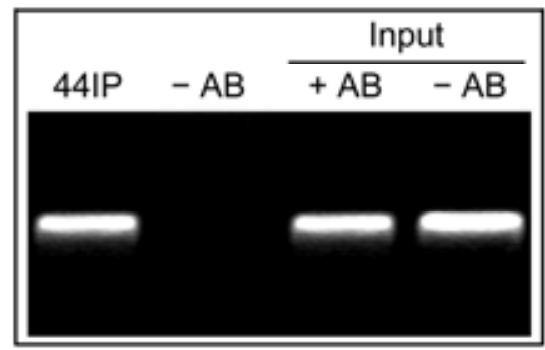

B

\begin{tabular}{|c|c|c|c|c|c|}
\hline \multicolumn{6}{|c|}{ BI-WT-P $\left(5 \times 10^{-8} \mu \mathrm{mol}\right)+$ AtMYB44 $\left(5 \times 10^{-2} \mu \mathrm{mol}\right)+$} \\
\hline WT-P $(5 \times \mu \mathrm{mol})$ & $10^{-2}$ & $10^{-4}$ & $10^{-6}$ & $10^{-8}$ & $10^{-10}$ \\
\hline BI-WT-P+AtMYB44 $\rightarrow$ & & & & & \\
\hline
\end{tabular}

C

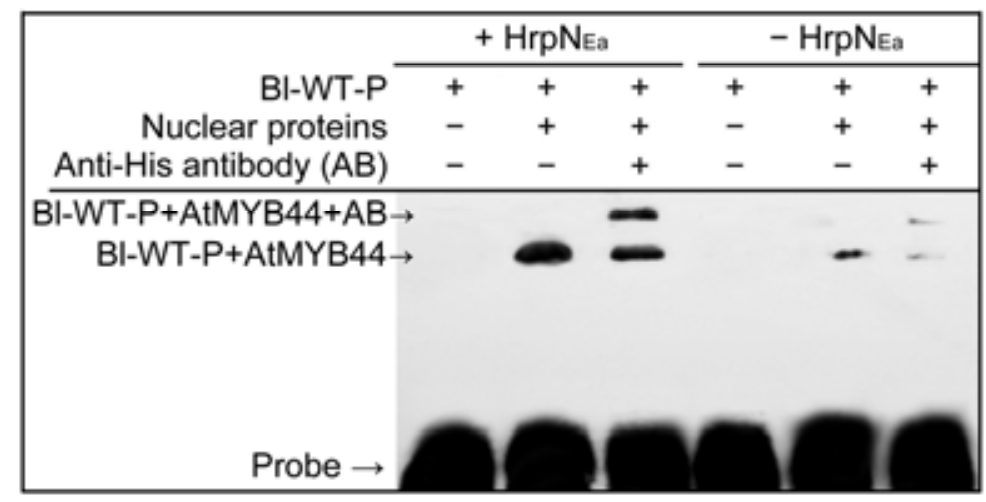

Fig. 6. Tests of the AtMYB44-EIN2 interaction. A through C, Gel mobility shift assay (GMSA) shows activity of AtMYB44 to bind the probe specific to EIN2 promoter. A, Reactions in this GMSA contained the following reagents or their combinations: WT-P = unlabeled WT (wild type) oligonucleotide probe, B1-WT-P = biotin-labeled WT probe, Mt-P = unlabeled mutant probe, B1-Mt-P = biotin-labeled mutant probe, AtMYB44 = the AtMYB44-His fusion protein partially purified. Labeled probes, unlabeled probes, and AtMYB44 were used at $5 \times 10^{-8}, 5 \times 10^{-6}$, and $5 \times 10^{-2} \mu \mathrm{mol}$. B, Reactions in this GMSA are indicated and labels are the same as in A. C, Reactions in this GMSA contained combinations of $5 \times 10^{-6} \mu \mathrm{mol}$ B1-WT-P, 50 ng of specific anti-His antibody, and $3 \mu \mathrm{g}$ of nuclear proteins isolated from Catmyb44-2 plants $12 \mathrm{~h}$ posttreatment (hpt) with $\mathrm{HrpN}_{\mathrm{Ea}}(+\mathrm{HrpN} \mathrm{Ea})$ or empty vector preparation $\left(-\mathrm{HrpN} \mathrm{N}_{\mathrm{Ea}}\right)$. D, Chromatin immunoprecipitation (ChIP) polymerase chain reaction (PCR) analysis was conduced with chromatins isolated at 12 hpt from $\mathrm{HrpN} \mathrm{Ea}_{\text {-treated }}$ Catmyb44-2 plants, the specific anti-His antibody, and EIN2-specific primers. Bands in gel indicate products of PCR conducted with DNA templates from the immunoprecipitation complex 44IP (chromatin DNA+AtMYB44::His+antibody), the mock precipitation in the absence of the antibody (-AB), chromatins before immunoprecipitation (input, $-\mathrm{AB}$ ), and the supernatant from the immunoprecipitation (input, $+\mathrm{AB}$ ). 
scripts showing successive increases in the subsequent $15 \mathrm{~h}$ (analysis of variance [ANOVA] test, $P<0.01$ ). This result confirmed the AtMYB44-dependent EIN2 expression and coordinate behaviors of both genes at the transcription level.

AtMYB44 overexpression differentially affects EIN2 expression under different genetic backgrounds of ethylene insensitivity.

For use in a study to situate AtMYB44 in the ethylene-signaling pathway, we created five types of AtMYB44-overexpres- sion Arabidopsis transgenic plants via transformation with the $35 S:: W T$ 44CDS::His construct. The five types of transgenic plants, designated as MYB44OTA, MYB44 etr1-1, MYB44 ein2-1, MYB44 ein3-1, and MYB44 ein5-1, were generated in sequence under backgrounds of WT and ethylene-insensitive etr1-1, ein2-1, ein3-1, and ein5-1 mutants of Arabidopsis. All of these transgenic plants had evident overexpression of the AtMYB44 gene, produced abundant amounts of the AtMYB44His fusion protein (Fig. 8A), and had the AtMYB44-EIN2 interaction detectable by the ChIP assay using His-specific
A

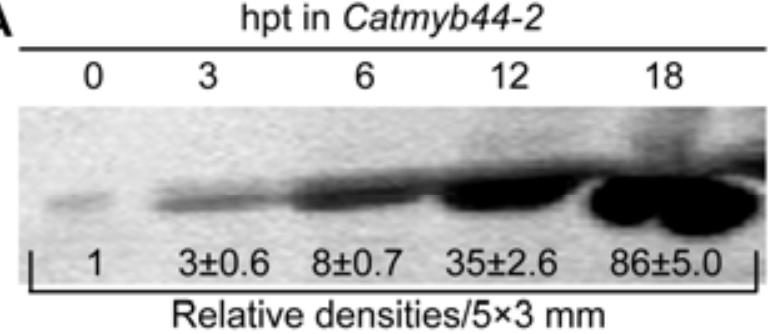

B

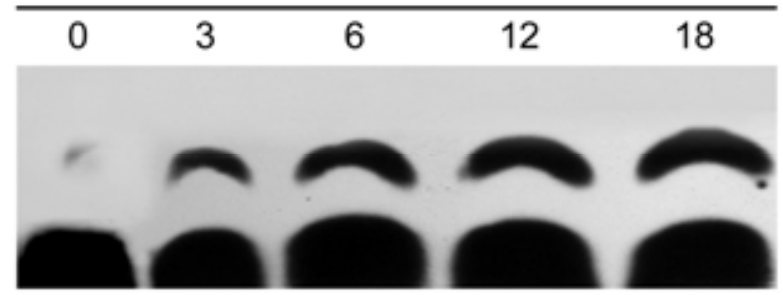

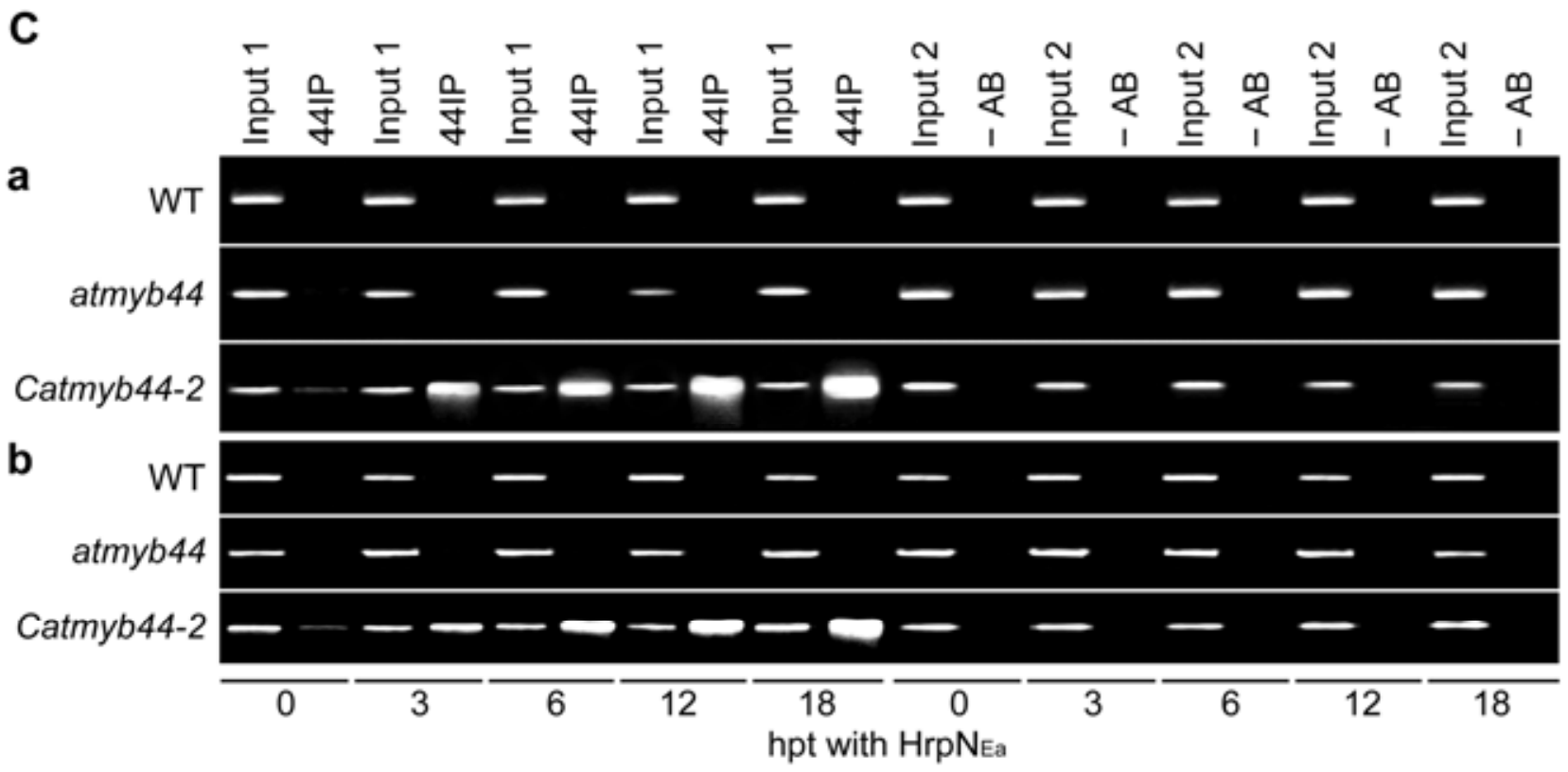

D

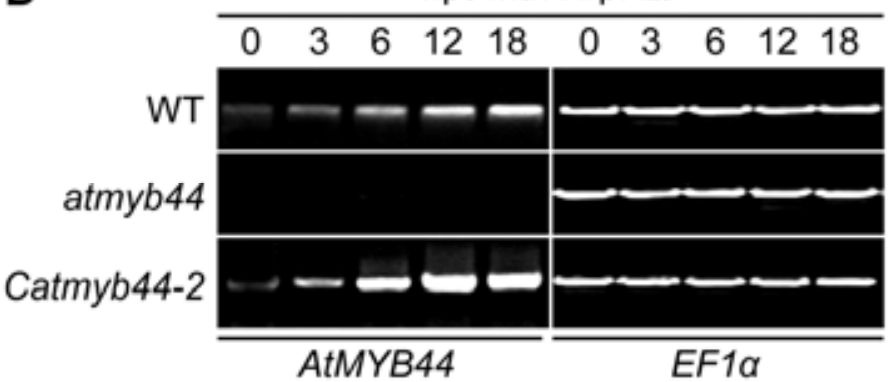

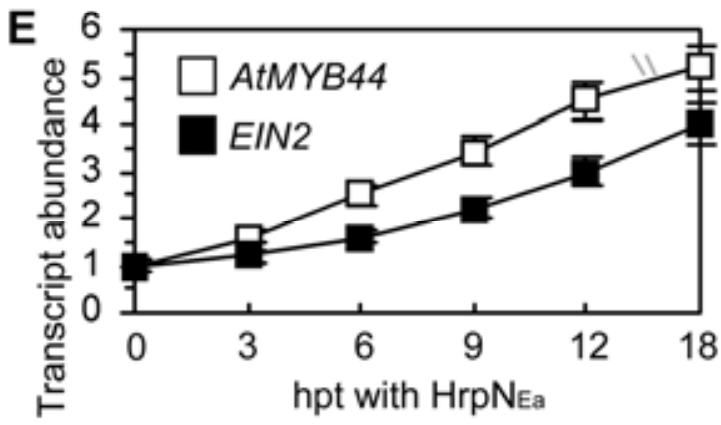

Fig. 7. Coordinate induction of AtMYB44-EIN2 interaction and expression of AtMYB44 and EIN2 genes. A, In the gel electrophoresis, the AtMYB44-His fusion protein loaded in each panel had been purified from nuclear proteins isolated from $2 \mathrm{~g}$ of plant leaves treated with HrpN $\mathrm{Ea}_{\mathrm{Ea}}$. Densities (means \pm standard deviations [SD], three repeats, 15 plants per repeat) of product bands were determined with a gel documentation system. B, Each reaction solution used in this gel mobility shift assay contained $3 \mu \mathrm{g}$ of Catmyb44-2 nuclear proteins from A, anti-His antibody of $5 \times 10^{-6} \mu$ mol and biotin-labeled WT probe of $5 \times$ $10^{-8} \mu \mathrm{mol}$. C, Chromatin immunoprecipitation polymerase chain reaction (PCR) analysis was conducted with chromatins isolated at the indicated times from $\mathrm{HrpN}_{\mathrm{Ea}}$-treated plants of the indicated genotypes, the specific anti-His antibody, and primers specific to EIN2 coding sequences (section a) and the promoter region (section b). Bands in gel indicate products of PCR conducted with DNA templates from 44IP, the mock precipitation in the absence of the antibody (-AB), the supernatant from the immunoprecipitation (input 1), and chromatins before immunoprecipitation (input 2), respectively. D, Reverse transcriptase (RT)PCR analyses of gene expression in the indicated plants. E, Gene expression in Catmyb44-2 was analyzed by real-time RT-PCR. Transcript abundance was given as 1 for empty vector preparation-treated WT and was scored (mean $\pm \mathrm{SD}$, three repeats, 15 plants per repeat) accordingly for other plants. 
antibody (Fig. 8B). However, AtMYB44 overexpression had different impacts on EIN2 expression, depending on the background genotype (Fig. 8C). Greater levels of EIN2 transcription were observed in MYB44OTA than in WT (Fig. 8C).
MYB44 etrl-1 and MYB44 ein2-1 were similar to etrl-1 and ein2-1; they had less EIN2 transcript (Fig. 8C). Thus, AtMYB44 overexpression did affect EIN2 expression under backgrounds of etrl-1 and ein2-1. In contrast, AtMYB44 overexpression in
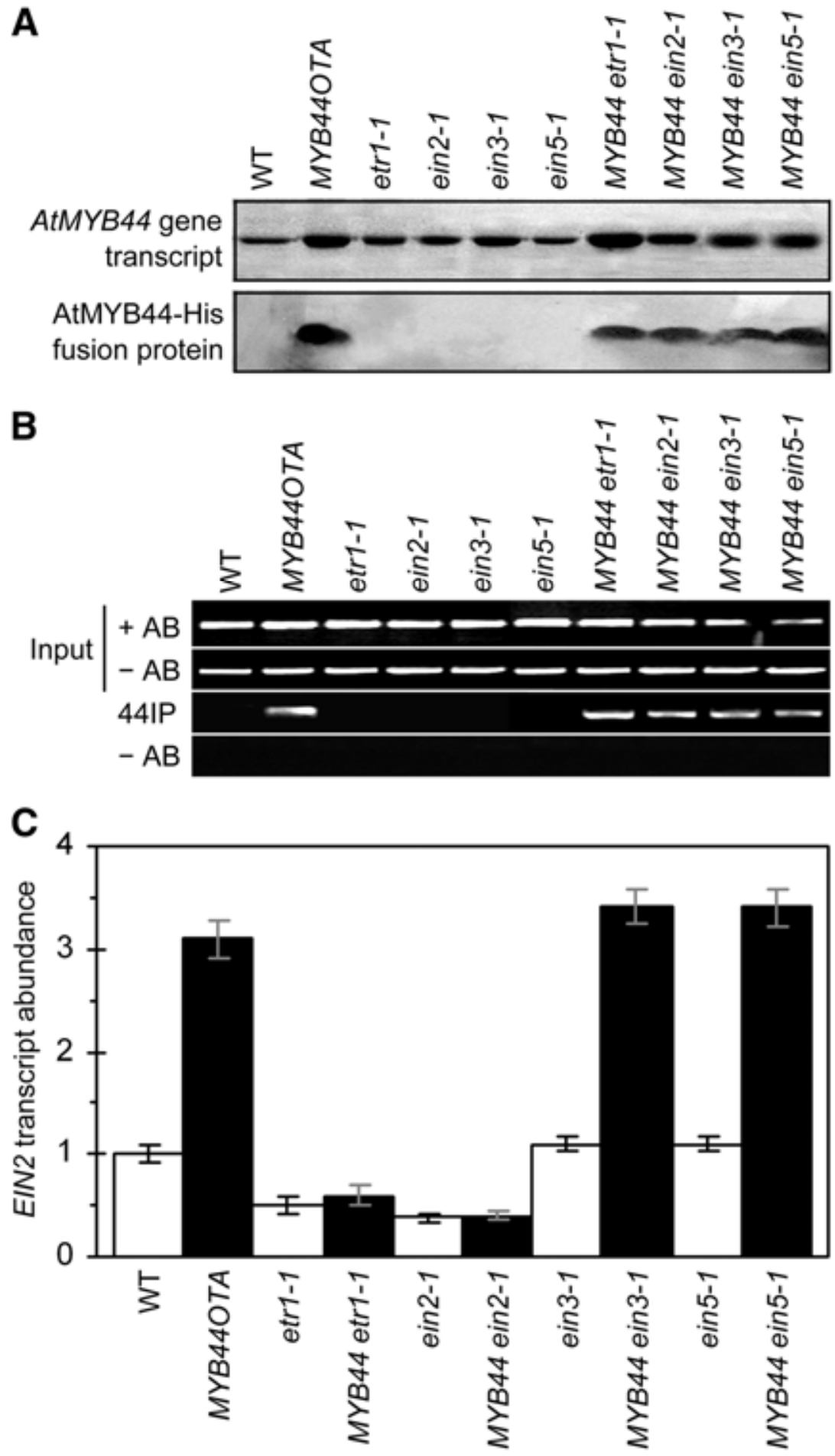

Fig. 8. Effects of AtMYB44 overexpression on EIN2 expression under the different genetic backgrounds of Arabidopsis. AtMYB44 overexpression Arabidopsis MYB44OAT, MYB44 etr1-1, MYB44 ein2-1, MYB44 ein3-1, and MYB44 ein5-1 were generated by introducing the $35 S:: 44 C D S:: H i s$ construct into wild type (WT) and the ethylene-insensitive etr1-1, ein2-1, ein3-1, and ein5-1 mutants, respectively. Transgenic plants were compared with WT and cognate mutants in terms of EIN2 expression. A, A Northern blot analysis of the gene and a Western blot of the protein from the indicated plants. The Northern blot was hybridized with a digoxigenin-labeled AtMYB44-specific probe, and the Western blot was incubated with anti-His antibody and was hybridized with horseradish peroxidase-conjugated goat antimouse immunoglobulin G. B, Chromatin immunoprecipitation assays involved chromatin samples from the plants indicated on top, anti-His antibody (AB), and EIN2-specific primers. Bands in gel indicate products of polymerase chain reaction (PCR) conducted with EIN2 DNA from chromatin (input) and from the immunoprecipitation complex (44IP) in the presence (+) and absence (-) of AB. C, Real-time reverse transcriptase-PCR was used to quantify levels of constitutive EIN2 expression. Transcript abundance was defined as 1 for WT and was scored accordingly for other plants. Data represent means \pm standard deviations (three repeats, 15 plants per repeat). 
ein3-1 and ein5-1 resulted in marked increases in EIN2 expression (Fig. 8C).

\section{DISCUSSION}

A large number of transcription factors identified from plants are known to function in association with distinct phytohormones (Qu and Zhu 2006). Increasing attention has been paid to physiological linkages between particular hormones and transcription factors (Abe et al. 2003; Cheng et al. 2009). The present study reveals that AtMYB44 regulates the induction of EIN2 transcription in an ethylene-dependent manner in $\mathrm{HrpN}_{\mathrm{Ea}^{-}}$ treated Arabidopsis. This demonstration establishes a physiological connection between AtMYB44 and the ethylene signal transduction pathway.

The functional relationship between AtMYB44 and EIN2 has been elucidated by several lines of evidence. First, both genes coordinate their responses to $\mathrm{HrpN}_{\mathrm{Ea}}$ in WT and Catmyb44 (Figs. 1 to 5). In Catmyb44 plants responding to $\mathrm{HrpN}_{\mathrm{Ea}}$ or ethylene, nuclear localization of AtMYB44 and expression of EIN2 are concomitant (Fig. 3). Second, the GMSA results reveal that AtMYB44 produced by prokaryotic expression specifically binds the probe specific for CMRS (Fig. 6). CMRS is present in the EIN2 promoter and is one of the MYB recognition sequences. MYB recognition sequences fall into at least three categories: i) CMRS, 5'-TAACTG-3' (Urao et al. 1993, 1996; Hoeren et al. 1998; Abe et al. 2003); ii) CMRS, 5'(A)AACC(A)-3' (Hoeren et al. 1998; Serpa et al. 2007); and iii) MYB recognition sequence type I, 5'-CNGTT(A/G)-3'; type II, 5'-G(G/T)T(A/T)GTT(A/G)-3'; and type IIG, 5'G(G/T)T(A/T)GGT(A/G)-3' (Agarwal et al. 2006; Romero et al. 1998;). Third, MYB proteins have binding specificity to one of these MYB recognition sequences (Agarwal et al. 2006; Romero et al. 1998). The ChIP protocol detects the interaction

\section{HrpNea stilulation of the plant}
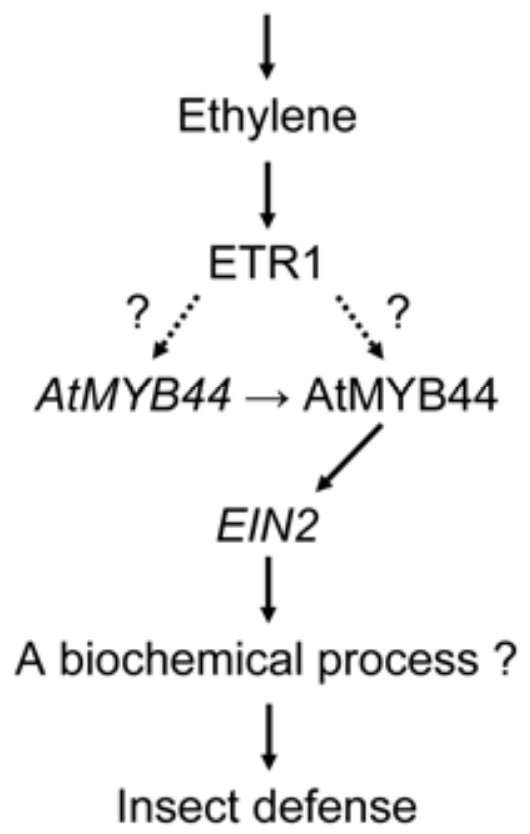

Fig. 9. A hypothetic process of EIN2 expression regulation by AtMYB44 in $\mathrm{HrpN}_{\mathrm{Ea}}$-treated Arabidopsis. The process is initiated by $\mathrm{HrpN}_{\mathrm{Ea}}$-induced elevation in the ethylene level and leads to insect defense of the plant. Arrowheads indicate the functional sequence of the signaling components Important questions include the possible effect of ETR1 on AtMYB44 or the protein and the biochemical event regulated by EIN2 to confer the insect defense phenotype. between AtMYB44 and chromatins from Catmyb44 in contrast to WT and atmyb44 (Figs. 6 and 7), offering additional evidence for the specific AtMYB44-EIN2 interaction. $\mathrm{HrpN}_{\mathrm{Ea}}$ treatment promotes AtMYB44 production, causes more binding of the EIN2 promoter, and elevates the gene expression level (Fig. 7). These results establish a physiological connection between AtMYB44 and EIN2 as a basis for regulation of $\mathrm{HrpN}_{\mathrm{Ea}}$-induced EIN2 transcription.

The interaction with EIN2 is specific for AtMYB44 under our study conditions. Of 37 transcription factor genes tested, AtMYB44 is the most $\mathrm{HrpN}_{\mathrm{Ea}}$ and ethylene responsive and is one of three $M Y B$ genes required for induced expression of the FPD1.2 gene (Liu et al. 2010). PDF1.2 is a molecular marker of ethylene and jasmonate signaling (Moran and Thompson 2001). The jasmonate level declines in $\mathrm{HrpN}_{\mathrm{Ea}}$-treated Arabidopsis plants (Dong et al. 1999). Jasmonate antagonizes the role of $\mathrm{HrpN}_{\mathrm{Ea}}$ in eliciting defense responses in tobacco cells (Andi et al. 2001). So it is likely that ethylene, rather than JA, is associated with induced $P D F 1.2$ expression in $\mathrm{HrpN}_{\mathrm{Ea}}{ }^{-}$ treated plants. $P D F 1.2$ is not expressed in ein2 mutants (Alonso et al. 1999), suggesting that EIN2 is required for PDF1.2 transcription. Although AtMYB15, AtMYB38, and $A t M Y B 44$ all affect FPD1.2 expression, only AtMYB44 is required for the $\mathrm{HrpN}_{\mathrm{Ea}^{-}}$or ethylene-induced EIN2 expression (Liu et al. 2010). Evidence has shown that AtMYB15 uses abscissic acid signaling and targets $\mathrm{CBF}$ genes to regulate freezing tolerance in plants (Ding et al. 2009; Miura and Hasegawa 2008; Miura et al. 2007). AtMYB15 prefers type II to types I and III of the MYB recognition sequence present in CBF genes (Agarwal et al. 2006). This finding suggests that the interaction between a MYB and a MYB recognition sequence present in a target gene is affected by the process that the MYB and target gene are regulating. The concept remains to be tested, especially for AtMYB44, which has at least 16 target genes identified recently (The Arabidopsis Information Resource website).

The relationship between AtMYB44 and ethylene signaling has been studied in relation to ETR1, EIN2, EIN3, and EIN5 (Fig. 8). ETR1 and EIN2 both are required for $\mathrm{HrpN}_{\mathrm{Ea}}$-induced insect defense (Dong et al. 2004). EIN3 is a nuclear-localized protein (Chao et al. 1997) that affects the expression of defense response genes such as PDF1.2 (Solano et al. 1998) and PRl (Chen et al. 2009), associated with plant resistance to insects and pathogens, respectively. In the ethylene-signaling pathway, EIN3 may act downstream of EIN2 to activate the ERF1 gene (Solano et al., 1998). EIN3 may also target the EBF1and EBF2 proteins; this function is regulated by EIN5 (Olmedo et al. 2006). EIN5 is an exoribonuclease (Olmedo et al. 2006; Potuschak et al. 2006) involved in response to $\mathrm{HrpN}_{\text {Ea }}$. In response, EIN5 confers plant growth enhancement, while EIN2 is responsible for insect defense (Dong et al. 2004). Investigations on the five types of AtMYB44-overexpression plants offer interesting information. AtMYB44 binding to the EIN2 promoter is not sufficient for the induction of the gene; ETR1 is also required, but EIN3 and EIN5 are dispensable (Fig. 8). Based on this result and previous studies, we propose that the regulation of EIN2 expression by AtMYB44 may operate as shown in Figure 9. The plant treatment with $\mathrm{HrpN}_{\mathrm{Ea}}$ elevates the ethylene level (Dong et al. 2004). ETR1 binding of ethylene (Bisson et al. 2009; Schaller and Bleecker 1995; Schaller et al. 1995) allows EIN2 to activate the downstream part of the signaling pathway (Wang et al. 2002). AtMYB44 expression leads to production of the protein, which functions, in turn, to activate EIN2 (Figs. 6 to 8). Insect defense is then induced (Dong et al. 2004), but the supposed intermediate process is unknown. Characterization of the supposed process is quite important, since biochemical function of 
EIN2 has remained a mystery over the past two decades (Alonso et al. 1999; Li et al. 2009; Wang et al. 2009).

\section{MATERIALS AND METHODS}

\section{Plant growth and treatment.}

Arabidopsis genotypes used in this study included ecotype Col-0, transgenic plants, atmyb44 mutant, and ethylene-insensitive etr1-1 (Bleecker et al. 1988), ein2-1 (Guzman and Ecker 1990), ein3-1 (Chao et al. 1997), and ein5-1 (Roman et al. 1995) mutants generated under the Col-0 background. All the plants were grown under $22^{\circ} \mathrm{C}$ and $200 \mu \mathrm{E} / \mathrm{m}^{2} / \mathrm{s}$ illumination (Ren et al. 2008; Zhang et al. 2007). For use in flowering observation and transformation, plants were grown in long-day conditions ( $16 \mathrm{~h}$ of light and $8 \mathrm{~h}$ of dark) until flowering. For other experiments, plants were grown in short-day conditions (with $12 \mathrm{~h}$ of light and $12 \mathrm{~h}$ of dark) for 40 days before use. Aqueous solutions of $\mathrm{HrpN}_{\mathrm{Ea}}$ and EVP were prepared (Dong et al. 1999) as $10 \mu \mathrm{g} / \mathrm{ml}$ aqueous solutions. Each solution was amended with surfactant Silwet-77 (0.02\%) and was applied by spraying plant tops with a low-pressure atomizer, unless specified. ACC was applied as per vender instruction (SigmaAldrich, St. Louis) at the amount for releasing gaseous ethylene at a rate of $22 \mu \mathrm{l} /$ liter to the plant growth environment in sealed glass jars. Pure water was used in the control. Ethylene collected from the plant growth environment was quantified by gas chromatography (Dong et al. 2004; Guzman and Ecker 1990).

\section{Gene expression analyses.}

Total RNA was isolated from plant tops and the top two leaves. Northern blots were hybridized to specific probes labeled with digoxigenin (Peng et al. 2004). RT-PCR was performed using specific primers (Supplementary Table S1) and superscript II RNAse $\mathrm{H}^{-}$reverse transcriptase (Invitrogen, San Diego, CA, U.S.A.). RT-PCR products were confirmed (Zhang et al. 2009). They were resolved by electrophoresis and were visualized with ethidium bromide. Previous methods were used in realtime RT-PCR (Wu et al. 2010) and transcript quantification (Livak and Schmittgen 2001). The EFl $\alpha$ (Peng et al. 2003) and ACTIN2 (Panchuk et al. 2005) genes were expressed stably under different study conditions (Liu et al. 2010; Peng et al. 2003, 2004; Wu et al. 2010) and were used as references. A tested gene transcript was quantified relative to those of $E F 1 \alpha$ and ACTIN2, respectively. Average expression level of the tested gene was defined as 1 for treatment controls or WT Arabidopsis to score levels of the gene transcript from different treatments or the other genotypes of the plant.

\section{Mutagenesis confirmation.}

The Arabidopsis atmyb44 mutant (TIER locus number AT5G67300) holds an AtMYB44 promoter disrupted by an insert of T-DNA (The Arabidopsis Information Resource website). T-DNA was introduced via transformation with the pROK2 vector, which contains $35 \mathrm{~S}$ and a kanamycin-resistant gene. Seeds (Stock no. SALK_008606) were provided as heterozygous at the locus. Homozygous progenies were screened using a regular protocol (Peng et al. 2004). The T-DNA insert was determined by PCR analysis of specific genes and by Southern blot analysis of genomic DNA.

\section{Gene construction.}

$44 P_{2000}$ and $44 C D S$ were cloned by PCR and RT-PCR using specific primers and genomic DNA and total RNA, respectively, isolated from WT Arabidopsis that had been treated three days earlier with $\mathrm{HrpN}_{\mathrm{Ea}}$. Sequences of PCR and RTPCR products were confirmed (Chen et al. 2008). The binary
pCAMBIA1301 vector (CAMBIA, Brisbane, Australia), which carries two copies of $35 \mathrm{~S}$ and a hygromycin-resistant gene $\left(H y G^{r}\right)$, was used to construct transformation units. For use in testing $44 P_{2000}$ activity, the $44 P_{2000}:: 44 C D S:: G F P$ unit was constructed and cloned into pCAMBIA1301, while both copies of $35 S$ were excised. The $35 S:: G F P$ gene fusion used as a control was made by direct cloning of GFP into the vector. For use in plant transformation, a His-tag coding for nine tandem histidines was added to the $3^{\prime}$ terminus of $44 P_{2000}: 44 C D S:$ : $G F P$, creating the $44 P_{2000}:: 44 C D S:: G F P:: H i s$ unit, which was cloned into pCAMBIA1301, while the right copy of $35 S$ was excised. For use in generation of AtMYB44 overexpression plants, $44 C D S$ fused to the His tag was cloned into pCAMBIA1301, while $35 S$ was conserved, producing the transcription unit $35 S:: 44 C D S:: H_{i(9)}$. These vectors were transferred separately into Agrobacterium tumefaciens EHA105 cells (Peng et al. 2004) for further use.

\section{Tests of $44 P_{2000}$ activity.}

Tests were done with onion peels and Arabidopsis roots, respectively. Onion peels were immersed in a suspension of EHA105 cells containing $35 S:: G F P$ and $44 P_{2000}: 44 C D S:: G F P::$ $\mathrm{His}$, respectively, in the presence of EVP or $\mathrm{HrpN}_{\mathrm{Ea}}$. After 48 $\mathrm{h}$, transformed onion peels were stained with 4,6-diamidino-2phenylindole (DAPI). Arabidopsis roots were immersed in a solution of EVP or $\mathrm{HrpN}_{\mathrm{Ea}}$ for $12 \mathrm{~h}$, followed by staining with DAPI. Both types of samples were observed by fluorescence microscopy to visualize DAPI-stained nuclei, using 365-nm excitation and a 395-nm chromatic beam splitter, and GFP fluorescence, using 475-nm excitation and a 500-nm chromatic beam splitter (Wang et al. 2009).

\section{Generation and characterization of transgenic plants.}

Flowering plants were used for transformation by blossom infiltration with a suspension of recombinant EHA105 cells. Catmyb44 was generated by transformation of atmyb44 with the pCAMBIA1301::44P $2000:: 44 C D S:: G F P:: H i$ s construct. MYB44OTA, MYB44 etr1-1, MYB44 etr2-1, MYB44 etr3-1, and $M Y B 44$ etr5-1 were generated by transformation of WT, etr1-1, ein2-1, ein3-1, and ein5-1 with the pCAMBIA1301:: $35 S:: 44 C D S:: H i$ s unit. Transgenic plants were screened, multiplied, and characterized by regular methods. T3 homozygous progeny were used in this study. Southern blots of genomic DNA were hybridized to a $H y G^{r}$-specific probe labeled with digoxigenin (Novagen, Madison, WI, U.S.A.). Western blots of proteins isolated from leaves (Liu et al. 2006) were hybridized with digoxigenin-labeled anti-GFP antibody (Novagen) or were incubated with anti-His antibody (Novagen) and hybridized with horseradish peroxidase-conjugated goat antimouse immunoglobulin $\mathrm{G}$ from the BeyoECL Plus kit (Beyotime Institute of Biotechnology, Haimen, China).

\section{GMSA.}

For use in GMSA, nuclear proteins were isolated from leaves (Fan and Dong 2002) and were quantified by the Coomassie brilliant blue assay (Bradford 1976). Total proteins were isolated from $2 \mathrm{~g}$ of plant leaves (Liu et al. 2006), and the AtMYB44-His fusion protein was produced by Escherichia coli cells containing pET30a(+)::His::AtMYBB44 vector. PET was made from $E$. coli cells harboring pET30a(+) only (Peng et al. 2003). Proteins were purified by nickel chromatography (Chen et al. 2008) and were quantified (Liu et al. 2006) and resolved by polyacrylamide gel electrophoresis (Chen et al. 2008). Total volumes of reagents were the same during manipulation of all protein samples. GMSA was done using the LightShift chemiluminescent GMSA kit (Pierce, Rockford, IL, U.S.A.). AtMYB44::His protein preparations, unpurified and 
partially purified, were tested in comparison with PET. Specific oligonucleotide probes were designed according to the CMRS (Urao et al. 1993). WT probe and the mutant were $5^{\prime}$ AACTATAGTAACTGTTTCTTCGTTAG-3' and 5'-AACTATA GacgtaaTTTCTTCGTTAG-3'. Probes were labeled with biotin using the Biotin $3^{\prime}$ end DNA labeling kit (Pierce). To test the in vitro AtMYB44 activity, GMSA was performed with PET, partially purified AtMYB44::His, and labeled WT probe. To test specificity in the activity of AtMYB44 to bind the primer, reactions were made of partially purified AtMYB44::His and unlabeled and labeled probes in combination or were made of anti-His antibody (Novagen), labeled WT probe, and plant nuclear proteins.

\section{ChIP.}

Chromatins used in the assay were isolated from Arabidopsis leaves as described (Benhamed et al. 2006). ChIP was conducted using the Epigenome protocol. Complexes of chromatin fragments and the AtMYB44-His protein (44IP complexes) were precipitated with the specific anti-His antibody (Santa Cruz Biotechnology, Santa Cruz, CA, U.S.A.) and the Protein A agarose/salmon sperm DNA beads (Millipore, Bedford, MA, U.S.A.). The 44IP complexes bound to the beads were collected by centrifuge. Concentrations of the antibody and chromatins were $10 \mu \mathrm{g}$ and $50 \mathrm{nM}$ per immunoprecipitation, respectively. Similar precipitation and centrifuge operations were done in the absence of the antibody in a negative experimental control. In positive experimental controls, chromatins without precipitation and the supernatant from the immunoprecipitation were used as inputs. DNA samples from 44IP, the negative control, and inputs were analyzed separately by PCR, using primers specific to the promoter $\left(44 P_{2000}\right)$ and CDS regions of EIN2. Sequences of PCR products were confirmed.

\section{Data treatment.}

Experiments were done at least three times with similar results. Quantitative data were analyzed by Student's $t$-test to compare treatments with $\mathrm{HrpN}_{\mathrm{Ea}}$ vs. EVP and specific transgenic plants vs. WT or atmyb44. Data were also analyzed by ANOVA to compare the plant genotypes. Both comparisons were used to evaluate differences in the effects of the $\mathrm{HrpN}_{\mathrm{Ea}}$ treatment or plant genotypes on levels of AtMYB44 and EIN2 expression. Both tests were performed at $P<0.05$ and $P<$ 0.01 , respectively.

\section{ACKNOWLEDGMENTS}

We thank S. V. Beer for critical comments, J. M. Bonasera for English editing, and J. Peng for bioinformatics information. This study was supported by National Science Foundation (30771441), Novel Transgenic Organisms Breeding Project (2009ZX08002-004B and 2008ZX08002001), and National High Technology Plan (863 Plan 2006AA10Z430) in China.

\section{LITERATURE CITED}

Abe, H., Urao, T., Ito, T., Seki, M., Shinozaki, K., and YamaguchiShinozaki, K. 2003. Arabidopsis AtMYC2 (bHLH) and AtMYB2 (MYB) function as transcriptional activators in abscisic acid signaling. Plant Cell 15:63-78.

Agarwal, M., Hao, Y., Kapoor, A., Dong, C. H., Fujii, H., Zheng, X., and Zhu, J. K. 2006. A R2R3 type MYB transcription factor is involved in the cold regulation of $\mathrm{CBF}$ genes and in acquired freezing tolerance. $J$. Biol. Chem. 281:37636-37645.

Alonso, J. M., Hirayama, T., Roman, G., Nourizadeh, S., and Ecker, J. R. 1999. EIN2, a bifunctional transducer of ethylene and stress responses in Arabidopsis. Science 284:2148-2152.

Andi, S., Taguchi, F., Toyoda, K., Shiraishi, T., and Ichinose, Y. 2001. Effect of methyl jasmonate on harpin-induced hypersensitive cell death, generation of hydrogen peroxide and expression of PAL mRNA in tobacco suspension cultured BY-2 cells. Plant Cell Physiol. 42:446-449.

Benhamed, M., Bertrand, C., Servet, C., and Zhou, D. X. 2006. Arabidopsis GCN5, HD1, and TAF1/HAF2 interact to regulate histone acetylation required for light-responsive gene expression. Plant Cell 18:2893-2903.

Bisson, M. M., Bleckmann, A., Allekotte, S., Groth, G. 2009. EIN2, the central regulator of ethylene signalling, is localized at the ER membrane where it interacts with the ethylene receptor ETR1. Biochem. J. 424:1-6.

Bleecker, A. B., Estelle, M. A., Somerville, C., and Kende, H. 1988. Insensitivity to ethylene conferred by a dominant mutation in Arabidopsis thaliana. Science 241:1086-1089.

Bradford, M. 1976. A rapid and sensitive method for the quantitation of microgram quantities of protein utilizing the principle of protein-dye binding. Anal. Biochem. 72:248-254.

Camehl, I., Sherameti, I., Venus, Y., Bethke, G., Varma, A., Lee, J., and Oelmüller, R. 2010. Ethylene signalling and ethylene-targeted transcription factors are required to balance beneficial and nonbeneficial traits in the symbiosis between the endophytic fungus Piriformospora indica and Arabidopsis thaliana. New Phytol. 185:1062-1073.

Chao, Q., Rothenberg, M., Solano, R., Roman, G., Terzaghi, W., and Ecker, J. R. 1997. Activation of the ethylene gas response pathway in Arabidopsis by the nuclear protein ETHYLENE-INSENSITIVE3 and related proteins. Cell 89:1133-1144.

Chen, H., Xue, L., Chintamanani, S., Germain, H., Lin, H., Cui, H., Cai, R., Zuo, J., Tang, X., Li, X., Guo, H., and Zhou J. M. 2009. ETHYLENE INSENSITIVE3 and ETHYLENE INSENSITIVE3-LIKE1 repress SALICYLIC ACID INDUCTION DEFICIENT2 expression to negatively regulate plant innate immunity in Arabidopsis. Plant Cell 21:2527-2540.

Chen, L., Qian, J., Qu, S., Long, J., Yin, Q., Zhang, C., Wu, X., Sun, F., Wu, T., Hayes, M., Beer, S. V., and Dong H. 2008. Identification of specific fragments of $\mathrm{HpaG}_{\mathrm{Xooc}}$, a harpin from Xanthomonas oryzae $\mathrm{pv}$. oryzicola, that induce disease resistance and enhance growth in plants. Phytopathology 98:781-791.

Chen, Y. H., Yang, X. Y., He, K., Liu, M. H., Li, J. G., Gao, Z. F., Lin, Z. Q., Zhang, Y. F., Wang, X. X., Qiu, X. M., Shen, Y. P., Zhang, L., Deng, X. H., Luo, J. C., Deng, X. W., Chen, Z. L., Gu, H. Y., and Qu, L. J. 2006. The MYB transcription factor superfamily of Arabidopsis: Expression analysis and phylogenetic comparison with the rice MYB family. Plant Mol. Biol. 60:107-124.

Cheng, H., Song, S., Xiao, L., Soo, H. M., Cheng, Z., Xie, D., and Peng, J. 2009. Gibberellin acts through jasmonate to control the expression of MYB21, MYB24, and MYB57 to promote stamen filament growth in Arabidopsis. PLoS Genet. 5:e1000440. Published online.

Ding, Z., Li, S., An, X., Liu, X., Qin, H., and Wang, D. 2009. Transgenic expression of MYB15 confers enhanced sensitivity to abscisic acid and improved drought tolerance in Arabidopsis thaliana. J. Genet. Genomics 36:17-29.

Dong, H. P., Peng, J., Bao, Z., Meng, X., Bonasera, J. M., Chen, G., Beer, S. V., and Dong, H. 2004. Downstream divergence of the ethylene signaling pathway for harpin-stimulated Arabidopsis growth and insect defense. Plant Physiol. 136:3628-3638.

Dong, H. P., Yu, H., Bao, Z., Guo, X., Peng, J., Yao, Z., Chen, G., and Dong, H. 2005. The ABI2-dependent abscisic acid signalling controls HrpN-induced drought tolerance in Arabidopsis. Planta 221:313-327.

Dong, H., Delaney, T. P., Bauer, D. W., and Beer, S. V. 1999. Harpin induces disease resistance in Arabidopsis through the systemic acquired resistance pathway mediated by salicylic acid and the NIMI gene. Plant J. 20:207-215.

Fan, W., and Dong, X. 2002. In vivo interaction between NPR1 and transcription factor TGA2 leads to salicylic acid-mediated gene activation in Arabidopsis. Plant Cell 14:1377-1389.

Fuhrer, J., Kaur-Sawhney, R., Shih, L. M., and Galston, A. W. 1982. Effects of exogenous 1,3-diaminopropane and spermidine on senescence of oat leaves: II. Inhibition of ethylene biosynthesis and possible mode of action. Plant Physiol. 70:1597-1600.

Ghassemian, M., Nambara, E., Cutler, S., Kawaide, H., Kamiya, Y., and McCourt, P. 2000. Regulation of abscisic acid signaling by the ethylene response pathway in Arabidopsis. Plant Cell 12:1117-1126.

Guo, H., and Ecker, J. R. 2004. The ethylene signaling pathway: New insights. Curr. Opin. Plant Biol. 7:40-49.

Guzman, P., and Ecker, J. R. 1990. Exploiting the triple response of Arabidopsis to identify ethylene-related mutants. Plant Cell 2:513-523.

Hoeren, F. U., Dolferus, R., Wu, Y. R., Peacock, J., and Dennis, E. S. 1998. Evidence for a role for AtMYB2 in the induction of the Arabidopsis alcohol dehydrogenase gene $(A D H 1)$ by low oxygen. Genetics 149:479-490

Jung, C., Lyou, S. H., Yeu, S., Kim, M. A., Rhee, S., Kim, M, Lee, J. S., Choi, Y. D., and Cheong, J. J. 2007. Microarray-based screening of jasmonate-responsive genes in Arabidopsis thaliana. Plant Cell Rep. 26:1053-1063. 
Jung, C., Seo, J. S., Han, S. W., Koo, Y. J., Kim, C. H., Song, S. I., Nahm, B. H., Choi, Y. D., and Cheong, J. J. 2008. Overexpression of AtMYB44 enhances stomatal closure to confer abiotic stress tolerance in transgenic Arabidopsis. Plant Physiol. 146:623-635.

Jung, C., Shim, J. S., Seo, J. S., Lee, H. Y., Kim, C. H., Choi, Y. D., and Cheong, J. J. 2010. Non-specific phytohormonal induction of AtMYB44 and suppression of jasmonate-responsive gene activation in Arabidopsis thaliana. Mol. Cell 29:71-76.

Kim, J. F., and Beer, S. V. 2000. hrp genes and harpins of Erwinia amylovora: A decade of discovery. Pages 141-162 in: Fire Blight and Its Causative Agent, Erwinia amylovora. J. L. Vanneste, ed. CAB International, Wallingford, U.K.

Kirik, V., Kolle, K., Misera, S., and Baumlein, H. 1998. Two novel MYB homologues with changed expression in late embryogenesis-defective Arabidopsis mutants. Plant Mol. Biol. 37:819-827.

Kranz, H. D., Denekamp, M., Greco, R., Jin, H., Leyva, A., Meissner, R. C., Petroni, K., Urzainqui, A., Bevan, M., and Martin, C. 1998. Towards functional characterisation of the members of the R2R3-MYB gene family from Arabidopsis thaliana. Plant J. 16:263-276.

Leon-Reyes, A., Spoel, S. H., De Lange, E. S., Abe, H., Kobayashi, M., Tsuda, S., Millenaar, F. F., Welschen, R. A., Ritsema, T., and Pieterse, C. M. 2009. Ethylene modulates the role of NONEXPRESSOR OF PATHOGENESIS-RELATED GENES1 in cross talk between salicylate and jasmonate signaling. Plant Physiol. 149:1797-809.

Li, H., Wong, W. S., Zhu, L., Guo, H. W., Ecker, J., and Li, N. 2009. Phosphoproteomic analysis of ethylene-regulated protein phosphorylation in etiolated seedlings of Arabidopsis mutant ein2 using two-dimensional separations coupled with a hybrid quadrupole time-of-flight mass spectrometer. Proteomics 9:1646-1661.

Lin, Z., Zhong, S., and Grierson, D. 2009. Recent advances in ethylene research. J. Exp. Bot. 60:3311-3336.

Liu, F., Liu, H., Jia, Q., Wu, X., Guo, X., Zhang, S., Song, F., and Dong, H. 2006. The internal glycine-rich motif and cysteine suppress several effects of the $\mathrm{HpaG}_{\mathrm{Xooc}}$ protein in plants. Phytopathology 96:1052-1059.

Liu, R., Lü B., Wang, X., Zhang, C., Zhang, S., Qian, J., Chen, L., Shi, H., and Dong, H. 2010. Thirty-seven transcription factor genes differentially respond to a harpin protein and affect resistance to the green peach aphid in Arabidopsis. J. Biosci. 35:435-450.

Livak, K. J., and Schmittgen, T. D. 2001. Analysis of relative gene expression data using real-time quantitative PCR and the $2^{-\Delta \Delta \mathrm{Ct}}$ method. Methods 25:402-408.

Miura, K., and Hasegawa, P. M. 2008. Regulation of cold signaling by sumoylation of ICE1. Plant Signal. Behav. 3:52-53.

Miura, K., Jin J. B., Lee J., Yoo C. Y., Stirm V., Miura T., Ashworth E. N., Bressan R. A., Yun D. J., and Hasegawa P. M. 2007. SIZ1-mediated sumoylation of ICE1 controls CBF3/DREB1A expression and freezing tolerance in Arabidopsis. Plant Cell 19:1403-1414.

Moran, P. J., and Thompson, G. A. 2001. Molecular responses to aphid feeding in Arabidopsis in relation to plant defense pathways. Plant Physiol. 125:1074-1085.

Olmedo, G., Guo H. W., Gregory, B. D., Nourizadeh, S. D., AguilarHenonin, L., Li, H. J., An, F. Y., Guzman, P., and Ecker, J. R. 2006. ETHYLENE-INSENSITIVE5 encodes a 5' $\rightarrow 3^{\prime}$ exoribonuclease required for regulation of the EIN3-targeting F-box proteins EBF1/2. Proc. Natl. Acad. Sci. U.S.A. 103:13286-13293.

Panchuk, I. I., Zentgraf, U., and Volkov, R. A. 2005. Expression of the Apx gene family during leaf senescence of Arabidopsis thaliana. Planta 222:926-932.

Peng, J. L., Dong, H., Dong, H. P., Delaney, T. P., Bonasera, B. M., and Beer, S. V. 2003. Harpin-elicited hypersensitive cell death and pathogen resistance requires the NDR1 and EDS1 genes. Physiol. Mol. Plant Pathol. 62:317-326.

Peng, J., Bao, Z., Dong, H., Ren, H., and Wang, J. 2004. Expression of harpin $_{\mathrm{Xoo}}$ in transgenic tobacco induces pathogen defense in the absence of hypersensitive cell death. Phytopathology 94:1048-1055.

Penmetsa, R.V., Uribe, P., Anderson, J., Lichtenzveig, J., Gish, J. C., Nam, Y. W., Engstrom, E., Xu, K., Sckisel, G., Pereira, M., Baek, J. M., LopezMeyer, M., Long, S. R., Harrison, M. J., Singh, K. B., Kiss, G. B., and Cook, D. R. 2008. The Medicago truncatula ortholog of Arabidopsis EIN2, sickle, is a negative regulator of symbiotic and pathogenic microbial associations. Plant J. 55:580-595.

Pitzschke, A., Djamei, A., Teige, M., and Hirt, H. 2009. VIP1 response elements mediate mitogen-activated protein kinase 3-induced stress gene expression. Proc. Natl. Acad. Sci. U.S.A. 106:18414-18419.

Potuschak, T., Vansiri, A., Binder, B. M., Lechner, E., Vierstra, R. D., and Genschik, P. 2006. The exoribonuclease XRN4 is a component of the ethylene response pathway in Arabidopsis. Plant Cell 18:3047-3057.
Qiao, H., Chang, K. N., Yazaki, J., and Ecker, J. R. 2009. Interplay between ethylene, ETP1/ETP2 F-box proteins, and degradation of EIN2 triggers ethylene responses in Arabidopsis. Genes Dev. 23:512-521.

Qu, L. J., and Zhu, Y. X. 2006. Transcription factor families in Arabidopsis: Major progress and outstanding issues for future research. Curr. Opin. Plant Biol. 9:544-549.

Ren, X., Liu, F., Bao, Z., Zhang, C., Wu, X., Chen, L., Liu, R., and Dong, H. 2008. Root growth of Arabidopsis thaliana is regulated by ethylene and abscisic acid signaling interaction in response to $\mathrm{HrpN}_{\mathrm{Ea}}$, a bacterial protein of harpin group. Plant Mol. Biol. Rep. 26:225-240.

Roman, G., Lubarsky, B., Kieber, J. J., Rothenberg, M., and Ecker, J. R. 1995. Genetic analysis of ethylene signal transduction in Arabidopsis thaliana: Five novel mutant loci integrated into a stress response pathway. Genetics 139:1393-1409.

Romero, I., Fuertes, A., Benito, M. J., Malpica, J. M., Leyva, A., and PazAres, J. 1998. More than 80R2R3-MYB regulatory genes in the genome of Arabidopsis thaliana. Plant J. 14:273-284.

Schaller, G. E., and Bleecker, A. B. 1995. Ethylene-binding sites generated in yeast expressing the Arabidopsis ETR1 gene. Science 270:18091811.

Schaller, G. E., Ladd, A. N., Lanahan, M. B., Spanbauer, J. M., and Bleecker, A. B. 1995. The ethylene response mediator ETR1 from Arabidopsis forms a disulfide-linked dimer. J. Biol. Chem. 270:1252612530.

Serpa, V., Vernal, J., Lamattina, L., Grotewold, E., Cassia, R., and Terenzi, H. 2007. Inhibition of AtMYB2 DNA-binding by nitric oxide involves cysteine S-nitrosylation. Biochem. Biophys. Res. Commun. 361:1048-1053.

Solano, R., Stepanova, A., Chao, Q., Ecker, J. R. 1998. Nuclear events in ethylene signaling: A transcriptional cascade mediated by ETHYLENEINSENSITIVE3 and ETHYLENE-RESPONSE-FACTOR1. Genes Dev. 12:3703-3714.

Sun, P., Tian, Q. Y., Chen, J., and Zhang, W. H. 2010. Aluminium-induced inhibition of root elongation in Arabidopsis is mediated by ethylene and auxin. J. Exp. Bot. 61:347-356.

Urao, T., Kazuko, Y. S., Urao, S., and Shinozaki, K. 1993. An Arabidopsis myb homolog is induced by dehydration stress and its gene product binds to the conserved MYB recognition sequence. Plant Cell 5:15291539

Urao, T., Noji, M., Yamaguchi-Shinozaki, K., and Shinozaki, K. 1996. A transcriptional activation domain of ATMYB2, a drought-inducible Arabidopsis Myb-related protein. Plant J. 10:1145-1148.

Wang, K. L., Li, H., and Ecker, J. R. 2002. Ethylene biosynthesis and signaling networks. Plant Cell 14 Suppl.:S131-S151.

Wang, X., Kong, H., and Ma, H. 2009. F-box proteins regulate ethylene signaling and more. Genes Dev. 23:391-396.

Wang, Y., Liu, R., Chen, L., Wang, Y., Liang, Y. C., Wu, X., Li, B., Wu, J., Liang, Y., Wang, X., Zhang, C., Wang, Q., Hong, X., and Dong, H. 2009. Nicotiana tabacum TTG1 contributes to ParA1-induced signalling and cell death in leaf trichomes. J. Cell Sci. 122:2673-2685.

Wei, Z. M., Laby, R. J., Zumoff, C. H., Bauer, D. W., He, S. Y., Collmer, A., and Beer, S. V. 1992. Harpin, elicitor of the hypersensitive response produced by the plant pathogen Erwinia amylovora. Science 257:85-88.

Wu, T., Guo, A., Zhao, Y., Wang, X., Wang, Y., Zhao, D., Li, X., Ren, R., and Dong, H. 2010. Ectopic expression of the rice lumazine synthase gene contributes to defense responses in transgenic tobacco. Phytopathology 100:573-581.

Zhang, C., Bao, Z., Liang, Y., Yang, X., Wu, X., Hong, X., and Dong, H. 2007. Abscisic acid mediates Arabidopsis drought tolerance induced by $\mathrm{HrpN}_{\mathrm{Ea}}$ in the absence of ethylene signaling. Plant Mol. Biol. Rep. 25:98-114.

Zhang, C., Shi, H., Chen, L., Wang, X., Lü, B., Zhang, S., Liang, Y., Liu, R., Qian, J., Sun, W., You, Z., and Dong, H. Harpin-induced expression and transgenic overexpression of the phloem protein gene AtPP2-A1 in Arabidopsis repress phloem feeding of the green peach aphid Myzus persicae. BMC Plant Biol. In press.

Zhang, S. J., Yang, X., Sun, M. W., Sun, F., Deng, S., and Dong, H. 2009. Riboflavin-induced priming for pathogen defense in Arabidopsis thaliana. J. Integr. Plant Biol. 51:167-174.

Zhu, Z., and Guo, H. 2008. Genetic basis of ethylene perception and signal transduction in Arabidopsis. J. Integr. Plant Biol. 50:808-815.

\section{AUTHOR-RECOMMENDED INTERNET RESOURCES}

The Arabidopsis Information Resource website: www.arabidopsis.org The Epigenome website: www.epigenome-noe.net 